NASA

Technical Memorandum 87237
USAAVSCOM

Technical Report 85-C-21

\title{
Effect of Area Ratio on the Performance of a 5.5:1 Pressure Ratio Centrifugal Impeller
}

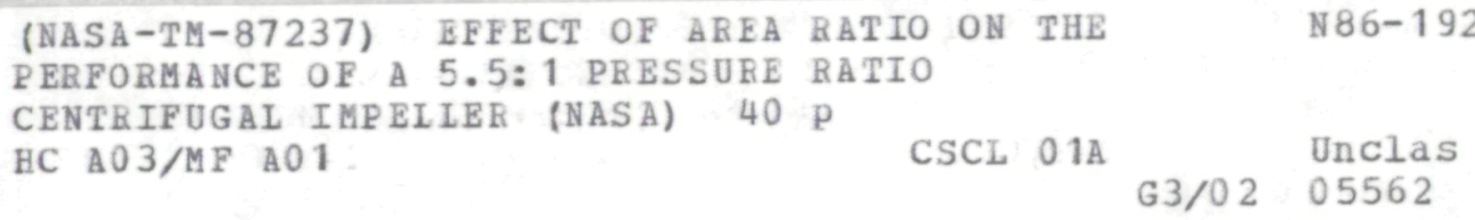

Lawrence F. Schumann and David A. Clark

Propulsion Directorate

U.S. Army Aviation Research and Technology Activity-AVSCOM

Lewis Research Center

Cleveland, Ohio

and

Jerry R. Wood

Lewis Research Center

Cleveland, Ohio

Prepared for the

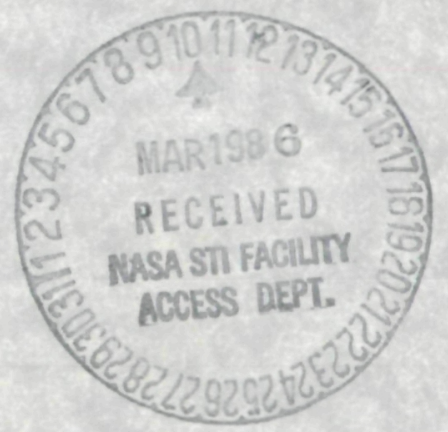

31st International Gas Turbine Conference and Exhibition sponsored by the American Society of Mechanical Engineers Dusseldorf, West Germany, June 8-12, 1986

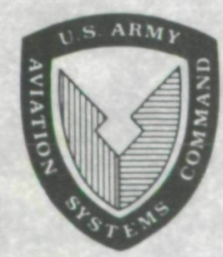


EFFECT OF AREA RATIO ON THE PERFORMANCE" OF A 5.5:1 PRESSURE

\author{
$\because$. . RATIO .CENTRIFUGAL IMPEILLER' \\ Lawrence F. Schumann and David A. Clark. \\ Propulsion Directorate \\ U. S. Army Aviation Research and Technology Activity - AvSCOM \\ Lewis Research Center \\ Cleveland, Ohio 44135
}

and

Jerry R.' Wood

National Aeronautics and Space Administration

Lewis Research Center

Cleveland, Ohio 44135

\title{
SUMMARY
}

A centrifugal impeller which was initially designed for a pressure ratio of approximately 5.5 and a mass flow rate of $0.959 \mathrm{~kg} / \mathrm{sec}$ was tested with a vaneless diffuser for a range of design point impeller area ratios from 2.322 to 2.945. The impeller area ratio was changed by successively cutting back the impeller exit axial width from an initial value of $7.57 \mathrm{~mm}$ to a final value of $5.97 \mathrm{~mm}$. In all, four separate area ratios were tested. For each area ratio a series of impeller exit axial clearances was also tested. Test results are based on impeller exit surveys of total pressure, total temperature, and flow angle at a radius 1.115 times the impeller exit radius.

Results of the tests at design speed, peak efficiency, and an exit tip clearance of 8 percent of exit blade height show that the impeller equivalent pressure recovery coefficient peaked at a design point area ratio of approxi-mately 2.748 while the impeller aerodynamic efficiency peaked at a lower value of area ratio of approximately 2.55. The variation of impeller efficiency with clearance showed expected trends with a loss of approximately, 0.4 , points in impeller efficiency for each percent increase in exit axial tip clearance for all impellers tested. The data also indicated that the impeller would probably separate at design area ratios greater than 2.748 . An analysis was performed with a quasi-three-dimensional inviscid computer code which confirmed that a minimum velocity ratio was attained near this area ratio thus indicating separation. This data can be used to verify impeller flow models which attempt to account for very high diffusion and possible separation.

\section{NOMENCLATURE}

A geometric area, $\mathrm{m}^{2}$

AR impeller equivalent area ratio at design flow rate, $\frac{P_{2}^{\prime \prime}}{P_{1}^{\prime \prime}} \sqrt{\frac{T_{1 T}^{\prime \prime}}{T_{2}^{\prime \prime}}} \frac{A_{2}}{A_{1 T}}$

AlT impeller inlet tip flow area, $\dot{\mathrm{m}} / \mathrm{p}_{1} \mathrm{~T}^{\mathrm{W}} \mathrm{T}$

b impeller blade height, $\mathrm{mm}$ 
CL impeller exit tip clearance, $\mathrm{mm}$

CPIMP impeller equivalent static pressure recovery coefficient, $\left(\frac{P_{2}}{P_{1 T}} \frac{P_{1 T}^{\prime \prime}}{P_{2}^{\prime \prime}}-1\right) /\left(\frac{P_{1 T}^{\prime \prime}}{P_{1 T}}-1\right)$

entha 1py, J/kg

$\dot{\mathrm{m}}$ mass flow rate, $\mathrm{kg} / \mathrm{sec}$

$\mathrm{N}_{\mathrm{S}} \quad$ specific speed, $\omega \sqrt{\mathrm{m} / \mathrm{\rho}^{\prime} \mathrm{o}^{/ \Delta h_{I 0}}} 3 / 4$

$\mathrm{P} \quad$ pressure, $\mathrm{Nt} / \mathrm{m}^{2}$

$r$ radius, $\mathrm{mm}$

$T$ temperature, $K$

$U$ wheel speed, $\mathrm{m} / \mathrm{sec}$

$v$ absolute velocity, $\mathrm{m} / \mathrm{sec}$

W relative velocity, $\mathrm{m} / \mathrm{sec}$

2. axial coordinates, $\mathrm{mm}$

a absolute flow angle, degrees

B relative flow angle, degrees

${ }_{C L}$ impeller exit tip deflection, $\mathrm{mm}$

$\delta \quad$ ratio of inlet total pressure to U.S. standard sea level pressure

$n \quad$ efficiency

$\theta$ ratio of inlet total temperature to U.S. standard sea level temperature

$\rho$ density, $\mathrm{kg} / \mathrm{m}^{3}$

$\omega \quad$ impeller angular velocity, $1 / \mathrm{sec}$

Subscripts:

a average

cr conditions at the critical state

DES design

H hub

ID ideal 


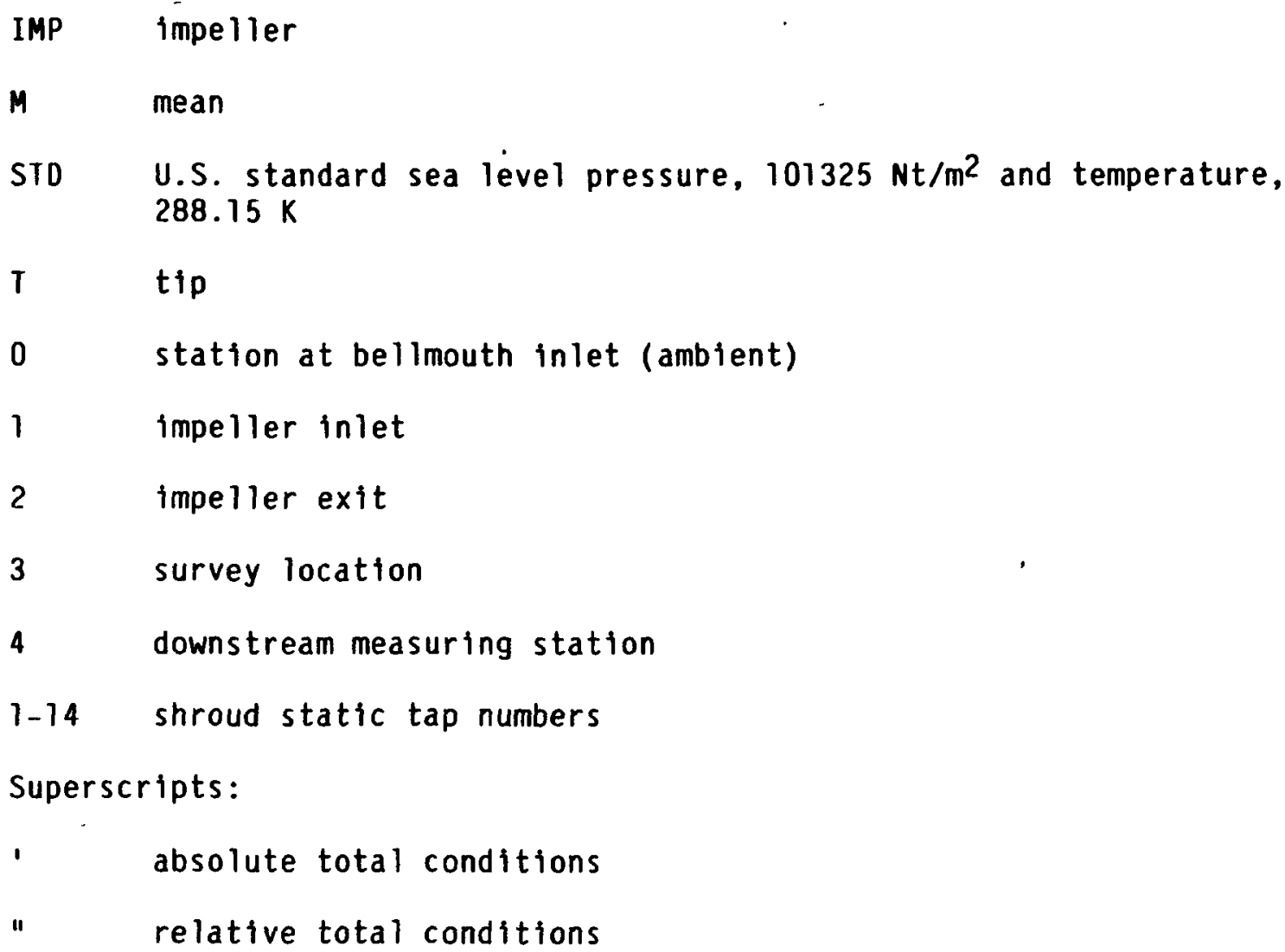

In the design of centrifugal impellers, several geometric parameters must be specified. Some of these, such as impeller inlet and exit radii, are fixed by design constraints of pressure ratio, mass flow and any geometrical limits imposed by the configuration. Others such as impeller exit blade height, impeller exit blade sweepback, number of blades, and impeller rotative speed can be chosen by the designer in order to optimize the particular stage within limits dictated by stress or turbine matching considerations. Studies have been done in the past which indicate the trends of impeller efficiency with specific speed (refs. 1 and 2), with impeller backsweep (ref. 2), and with impeller relative velocity distribution (ref. 3 ).

The subject of this paper is the variation of impeller performance with impeller area ratio. The data should be useful for evaluating the ability of an advanced computer code to calculate the outlet flow field of a series of impellers which have only a single geometric parameter varied. The area ratio was varied over a large range because data was desired that would include the effect of a large global separation in the impeller. These type of data would be useful in developing flow models that can describe the flow behavior in an impeller that approaches or operates with large amounts of separation. The data on clearance effects should also be useful for checking clearance models.

The equivalent area ratio is defined as the geometric area ratio needed to provide the equivalent amount of relative diffusion for a rotating impeller as in a nonrotating diffuser. Thus a change in equivalent area ratio is indicative of a change in relative velocity ratio. For a low diffusion impeller 
(1.e., a low ratio of inlet tip relative Mach number to exit relative Mach number), the boundary layer growth in the impeller will be small but the Mach number levels will be high. Also, since less diffusion is done in the impeller, more diffusion must be done in the diffusing system to achieve the same static pressure level.

On the other hand, for high diffusion impellers, although Mach number levels and clearance losses may be less, the impeller boundary layer growth may be large. For excessively large area ratios, the impeller boundary layers may separate and cause a decrease in impeller performance and, thus, a negative effect on diffuser performance. Therefore, the trade-offs involved in choosing between low diffusion and high diffusion indicate that an optimum area ratio may exist.

For this study, the exit passage width of an impeller with a nominal total pressure ratio of 5.5 was successively cut back while maintaining the same tip contour. This effectively reduced the equivalent area ratio of the impeller from an initial value of 2.945 to a final value of 2.322 . For each of the four impeller configurations, three values of impeller exit tip clearance were tested to establish the effect of clearance on overall performance and on the flow profiles at impeller exit.

Comparisons were made among the four impeller exit spanwise survey measurements to determine the effect of area ratio and clearance on impeller performance. Comparisons are based on derived impeller exit total pressure and efficiency and mass-averaged performance parameters at the downstream survey location.

\section{IMPELLER AERODYNAMIC DESIGN}

The baseline impeller is a scaled-up (scale factor $=1.2588$ ) version of an impeller designed for use in an automotive gas turbine engine. The original version of the impeller had 18 blades and its aerodynamic design is described in reference 4. The impeller was subsequently modified to include a splitter blade in order to reduce impeller blade loading. This modified impeller was also reduced in exit radius in order to maintain the same work input; however, the impeller main blade shapes and hub and shroud contours were not changed. The splitter blade leading edge was biased toward the suction surface of the main blade in order to equalize the mass flow rate in the splitter channels. The splitter blade shape was then faired into the main blade shape at a specified distance downstream from the splitter leading edge. The computer code of reference 5 was used to determine the bias and fairing schedule that would produce reasonable splitter leading edge velocities with an equal mass flow rate split. The detailed blade coordinates and impeller mechanical design for the baseline impeller are presented in reference 6 .

The initial bulld of the impeller had an exit radius and exit blade height $2.54 \mathrm{~mm}$ larger than the baseline impeller (fig. 1). The blade shape was obtained by extrapolating the baseline blade. The overall geometry of the initial build of the impeller was as follows: 
Number of main blades/splitter

blades .......... . 18/18

Inlet tip diameter, mm . . . . . 112.52

Inlet hub/tip ratio ....... . . . . . . . .

Exit tip diameter, mm . . . . . 208.02

Exit blade height, $\mathrm{mm}$. . . . . . 7.57

Backsweep angle, deg . . . . . 30.20

Design axial clearance/exit

blade height ......... . . . . . . .

Estimated performance: characteristics for Impeller $A$ are as follows:

Equivalent mass flow rate, $\mathrm{m} \sqrt{\theta} / \delta, \mathrm{kg} / \mathrm{sec} . . . . . .00 .959$

Impeller total pressure ratio, $\mathrm{P}_{2}{ }_{2} \mathrm{P}_{0}^{\prime}$.............. 5.50

Impeller static pressure ratio,

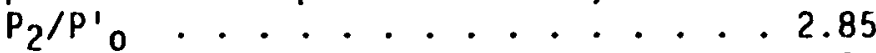

Impeller inlet aerodynamic blockage. . .02

Impeller total efficiency, n2 ... . . .903

Equivalent speed, $\mathrm{N} / \sqrt{\theta}, \mathrm{rpm}$. . 45,337.0

Specific speed, Ns $\quad .518$

The impeller design point velocity diagrams for the four impellers are shown in figure 2. A meridional view of the flow path and instrumentation locations is shown in figure 3 . The flow from the backswept centrifugal impeller is reduced in velocity in a constant area vaneless space before being dumped into a plenum at a radius ratio of $r / r_{2}=1.177$. The width of both the vaneless space and dump region change as the exit blade height of the impeller is changed and as the clearance is changed.

\section{APPARATUS, INSTRUMENTATION, AND PROCEDURE}

\section{Test Facility}

A schematic of the test facility is shown in figure 4 . The compressor and turbine are on a common shaft: Compressor mass flow rate was measured with a calibrated bellmouth on the compressor inlet. Compressor discharge pressure was manually controlled with a remotely operated valve in the compressor discharge line. Drive turbine speed was manually controlled by a valve on the turbine inlet line. Turbine discharge pressure was manually controlled by a remotely operated valve in the turbine discharge line.

\section{Instrumentation}

The compressor instrumentation stations are shown in figure 3 . Since ambient air enters the compressor inlet, local barometric pressure was used for the inlet total pressure. Inlet total temperature was measured with three bare-wire copper-constantan thermocouples spaced $120^{\circ}$ apart and attached to the bell-mouth. The downstream measurement station 4 was instrumented with six combination total temperature and total pressure probes evenly spaced about the circumference. The thermocouples were bare-wire chromel-alumel probes which were calibrated for Mach number effects. The total pressure tubes were 
chamfered to decrease angle sensitivity. The probes were set at an angle of approximately $80^{\circ}$ from radial so as to be oriented in the approximate direction of the highly swirling flow.

Static pressures were measured along the impeller shroud and through the vaneless space to the dump. A single row of taps was used on the shroud with an additional five taps spaced $6^{\circ}$ apart circumferentially just downstream of the impeller trailing edge $\left(r / r_{2}=1.014\right)$. At station $3\left(r_{3} / r_{2}=1.115\right)$ where survey data was taken, six static taps were spaced $6^{\circ}$ apart. Three static pressure taps were equally spaced at the downstream measurement station 4 . The radial locations of the static taps are shown on figure 3 .

Survey data at station 3 was taken using a miniature combination probe having total pressure, total temperature, and angle sensors. The pressure tubes were made from $0.508 \mathrm{~mm}$ diameter tubing and the total temperature probe was made from a $0.16 \mathrm{~mm}$ diameter chromel-alumel bare wire. The probe was nonnulling so it was necessary to calibrate it in a flow tunnel to determine corrections for total pressure, angle, and temperature versus indicated pressures from the angle sensor. The thermocouple was also calibrated for Mach number.

All thermocouple readings are referenced to an ice-bath temperature and are accurate to within $\pm 0.5^{\circ} \mathrm{F}$. Pressures were measured with a scannivalve system and were dynamically calibrated with a dead weight tester. The measured pressures should be accurate to within $\pm 0.06 \mathrm{Nt} / \mathrm{cm}^{2}$. For this study, repeatability of measurements is more important than absolute accuracy since trends are the desired result. Repeatability was judged to be good for this test.

\section{Impeller Configurations}

The impeller diffusion ratio was varied by changing the impeller exit blade height (b-width) and thus equivalent area ratio. This was done by successively modifying the impeller as shown in figure 1. The exit b-width was changed by axially translating the fabricating template for the impeller tip contour thus maintaining the same tip contour for all configurations. In all, four impeller exit b-widths were tested corresponding to four impeller diffusion ratios as shown in figure 1. In order to maintain the same impeller exit clearance, the shroud shims (shown in figure 3 ) had to be changed for each impeller exit b-width. Thus the vaneless diffuser width and the dump region width changed as the impeller b-width changed. The impeller exit clearance was also changed using the shroud shims. For each impeller b-width tested, three impeller exit clearances were tested. A list of the four impeller configurations tested along with the calculated area ratios and clearances tested for each impeller are shown in table 1 .

\section{Tip Clearance}

Impeller exit tip clearance was measured using graphite rub probes. The impeller tip deflected toward the shroud as impeller rotative speed increased. A plot of impeller deflection versus rotative speed is shown in figure 5 . The actual clearance was obtained by subtracting the impeller deflection from the 
cold set-up clearance. The deflection versus rotative speed curve was the same for all configurations tested.

\author{
Impeller Test
}

Ambient test cell air was used for the working fluid for all tests. Therefore, the inlet pressure was barometric and the inlet temperature was approximately $295 \mathrm{~K}$. Data was taken at speeds of $50,80,90$, and 100 percent of the design rotative speed. Mass flow rate was varied from open throttle to surge. Surge was indicated by an audible noise from the test cell. At 50 percent speed, no audible noise was detected and therefore surge could not be accurately determined.

\title{
Surveys
}

Impeller exit surveys were taken at a location downstream of the impeller tralling edge $\left(r_{3} / r_{2}=1.115\right)$. Data was taken every $0.51 \mathrm{~mm}$ from hub to tip, therefore more survey data points were taken for the high b-width impellers than for the low b-width impellers. Surveys were conducted at selected mass flow rates at speeds from 50 to 100 percent of design. Surveys were taken at approximately the same mass flow rates for each impeller configuration tested so that comparisons could be made. At each point in the survey, total temperature, total pressure, and flow angle were measured using the combination probe.

\section{Impeller Performance Calculation Procedure}

Based on calculated quantities. - The overall impeller map was derived from a calculated total pressure at the impeller exit and the measured downstream total temperature. This procedure was used since the time required to complete one survey was considerable and overall performance could be reasonably compared using this method since all the data was taken on the same test rig using the same instrumentation. Consequently, trends observed from these measurements should be correct for the configurations described herein. The total pressure was calculated from the measured impeller exit static pressure (an arithmetic average of the values from six static pressure taps), the measured downstream total temperature, impeller exit annulus area, and continuity assuming no impeller exit aerodynamic blockage. Results obtained with the survey probes indicate a heat loss between the survey location and the downstream measurement station. The temperature difference for the three clearances measured at each of the four b-widths varied from 0.5 to 1.5 percent of the mass average of the survey temperatures. The trends observed for temperature ratio versus area ratio and clearance were the same for both the mass average survey temperatures and measured downstream temperatures. A comparison of the temperatures measured at the downstream measurement station (station 4) and those based on mass averaged data at the survey location (station 3 ) for the four impeller configurations at design speed are shown in figure 6 .

Another measure of impeller performance is given by the equivalent pressure recovery coefficient. This quantity is a measure of the static pressure recovery of the impeller. It is defined in such a way as to remove the centrifugal contribution to the static pressure recovery and thus is a measure of the 
impeller's performance as a diffusing element. The equivalent pressure recovery coefficient is calculated for the tip streamline and thus values of the static pressure at the impeller inlet tip are required. These calculations were done using an axisymmetric duct calculation procedure at the impeller inlet. This procedure was also used in defining the impeller inlet tip flow area for use in the definition of impeller equivalent area ratio.

Based on survey measurements. - Survey measurements of total temperature, total pressure, and flow angle were taken downstream of the impeller trailing edge $\left(r_{3} / r_{2}=1.115\right)$. Static pressure was obtained from an arithmetic average of six static taps on the shroud side of the diffuser at the same radius as the survey probe. The static pressure was assumed to be constant across the diffuser passage at a constant radius. From the measured static and total pressures and total temperatures local values of velocity were obtained. These velocities together with the angle measurements from the survey and the geometric area allowed an integrated mass flow to be calculated. This integrated mass flow was compared to the measured mass flow and the measured flow angles were adjusted by a constant value across the passage until agreement was obtained. This was done since it was judged that the angle measurements were more uncertain than the other measurements taken. The amount of correction varied from 2.0 to $3.5^{\circ}$ for all flow points surveyed. Local values of radial and tangential velocities were then calculated from the calculated velocities and the corrected flow angles. Local efficiencies were calculated from the measured total pressures and total temperatures using curve fits on tables of gas properties. Averaged values of total efficiency, total pressure, velocity, and angle were then calculated using procedures described in the Appendix. The effect of the angle correction on the averaged efficiency was less than 0.25 points (a point is 1 percent in efficiency) and 0.5 percent in total pressure.

\section{RESULTS AND DISCUSSIONS}

\section{Overall Measurements}

For this investigation, four impeller configurations were tested. The configurations differed from each other only in the size of the exit b-width. All of the remaining geometry remained the same. For each value of impeller exit b-width, three separate values of impeller tip clearance were tested.

The overall impeller performance for the impeller with the highest b-width (designated Impeller A) and smallest clearance is shown in figure 7 . The performance maps for the other impeller configurations and other clearances are not shown since they are similar. The temperatures shown were for measurements at the downstream measurement station (station 4). Also shown are the mass averaged temperatures from the survey probe located at station 3 . These measurements were taken at selected mass flows and indicated temperatures which were up to 1-1/2 percent higher than those measured by the downstream thermo. couples. The compressor was surged for each of the speed lines shown; however. at 50 percent speed no audible surge was detected and therefore some data points may lie in a stalled region of the map. The calculated total pressure ratio peaked at a value of 5.75 for Impeller $A$ at a mass flow near surge (90 percent design mass flow rate) for the smallest clearance tested $\left(C L / b_{2}=0.023\right)$ at 100 percent design speed. Calculated impeller efficiency at 100 percent design speed also peaked at this mass flow rate and clearance 
at a value of 0.915 . For this reason all comparisons for impeller configurations were made at design speed and at a mass flow of 90 percent design mass flow. Also, comparisons at other mass flow rates and rotative speeds were found to be similar to those at the selected rotational speed and mass flow rate.

The variations of impeller efficiency and impeller equivalent pressure recovery coefficient with clearance and mass flow are shown in figures 8 and 9 for each of the four impeller configurations. The figures show an increase in pressure recovery coefficient and efficiency with decreasing clearance for each of the four impellers tested. The figures also show an increase in flow range from a value of about 17 percent for Impeller $A$ to a value of about 25 percent for Impeller $D$ at 100 percent design speed. There is no appreciable change in flow range with clearance for any of the impellers tested.

The data from figures 8 and 9 are cross plotted in figure 10 which shows the variation of efficiency and pressure recovery coefficient with clearance at a constant mass flow (near surge) for the four impeller configurations. The slopes of the curves are nearly identical for the four impeller configurations. The slopes of the impeller efficlency versus clearance curve shows a loss of approximately 0.4 points for every percent increase in with tip clearance. This agrees well with the value obtained for a 6-l pressure ratio impeller tested previously (ref. 7).

In order to compare the four impeller configurations, it is necessary to compare them at the same value of percent clearance at exit. Therefore, the data from the four impellers is cross-plotted to yield comparisons at nominal values of $\mathrm{CL} / \mathrm{b}_{2}$ of 0.08 and 0.06 . The results of this procedure are shown in figure 11 where the following parameters are plotted as a function of area ratio: calculated impeller efficlency; impeller equivalent pressure recovery coefficient; total temperature ratio; static and total pressure ratio; total efficiency; and average flow angle. With the exception of the pressure recov. ery coefficient and calculated impeller efficiency, these parameters are obtained from averages of survey measurements at station 3.

The equivalent pressure recovery coefficient increases rapidly up to an area ratio of 2.55 , continues to rise slightly up to an area ratio of 2.748 , then decreases from an area ratio of 2.748 to 2.945 . This is behavior typical for a stationary diffuser if area ratio is increased with no comparable increase in length. The pressure recovery coefficient increases rapidly until the diffuser approaches separation where peak recovery generally occurs. As area ratio continues to increase, pressure recovery falls as the diffuser experiences larger amounts of separation. From the equivalent pressure recovery curve, it can be concluded that global separation occurs in the impeller between the area ratios of 2.55 and 2.748. An examination of the temperature ratio plot also indicates a dramatic change in impeller behavior between these two area ratios (temperatures measured at station 4 were consistent with the averaged temperatures obtained at station 3 and indicated that the observed trends were not a result of scatter in the data) which is consistent with the onset of global separation. The static and total pressure ratios measured at station 3 are consistent with this observation. A dramatic effect is also observed for the averaged efficiency at station 3 for the 2.55 area ratio impeller. The curve shows a drop of about 0.8 points between the 2.322 and 2.55 area ratio impellers at 8 percent clearance and then an increase by 0.7 points from 2.55 to 2.748 area ratio. This drop in efficiency does not occur 
for the 6 percent clearance case and the average efficiency is relatively constant from 2.322 to 2.748 area ratio and then drops by several points at the highest area ratio. This behavior indicates a stronger effect of clearance at 2.55 than for the other area ratios tested. The behavior manifests itself in the average efficiency at station 3 but does not appear to affect the calculated impeller effictency. This implies one of two things: (1) either the vaneless space losses are more sensitive to clearance effects for this area ratio than they are for the other area ratios; or (2) the impeller, because of its proximity to its peak recovery point, is extremely sensitive to any perturbation such as an increased clearance and, since the calculated impeller efficiency is derived from the measured temperature and calculated impeller exit total pressure, the effect on calculated impeller efficiency is masked. The survey profiles for this area ratio indicate a dramatic effect with clear. ance as will be shown later. In figure 12 the impeller shroud static pressure is plotted versus mass flow ratio for the smallest clearance tested for each of the four impellers. Near the impeller exit, the plots for the two lower area ratio impellers ( $D$ and $C$ ) show a negative slope of pressure with mass flow rate while the plots for the higher area ratio impellers ( $A$ and $B$ ) show a zero slope near surge. In fact, the highest area ratio impeller shows a zero slope very close to the inducer region. This indicates that these two impellers may be separated at the low clearance.

\section{Survey Measurements}

The results of the surveys of total temperature, total pressure and flow angle are shown in figures 13 to 16 for the four impellers tested. The comparison point was chosen to be 100 percent design speed at a mass flow of 90 percent design mass flow. The figures show the measured values of total temperature, total pressure, and flow angle as well as the derived values of efficiency, radial velocity, and tangential velocity for each of the three clearances tested.

The survey results for the lowest area ratio tested (Impeller 0 , fig. 13) show profiles which are typical for nonseparated fully developed flow. There is an accumulation of low momentum fluid along the shroud which increases as the impeller tip clearance is increased. This causes the profiles to be skewed toward the hub side of the channel. The flow angles show that the flow remains attached although separation may be imminent near the shoud. The axial clearance near the shroud drastically affects the flow total pressure and total temperature over 80 percent of the channel height.

For the next higher area ratio tested (Impeller $C$, fig. 14) the flow appears to remain attached for the smallest clearance tested al though the flow along the hub has become more deficit causing a more symmetric profile. For the medium and large clearances, however, a large separation apparently occurs along the shroud which causes a large drop in total pressure and efficiency. This is probably what causes the large drop in efficiency in the cross-plotted data (fig. $11(f)$ ) going from Impeller $D$ to Impeller $C$. If a smaller clearance had been chosen for the cross plot, this drop in efficiency would have been much less and may not have occurred at all. 
The profiles for the impellers with the two highest area ratios tested (Impellers $A$ and $B$ ) are similar. Both impellers show fairly symmetric profiles with some slight skewing toward the hub as clearance is increased. The flow angle measurements show no significant regions of separation although separation is probably imminent on both hub and shroud. Another possible explanation of the profiles is that impeller separation has already occurred on both the hub and shroud and turbulent mixing has caused the profiles to assume a symmetric character.

A comparison of the survey profiles for the four impellers at the smallest clearances tested is shown in figure 17. The profiles are similar for the four impellers tested although the hub becomes more deficit as the b-width is increased. An examination of the temperature profiles shows that the temperature increases from Impellers $D$ to $C$ and also from Impellers $B$ to $A$. This would be expected since an increased b-width causes a decreased meridional velocity. For a backswept impeller with a constant deviation angle, this would cause the absolute tangential velocity to increase with increasing b-width. From Euler's work equation, this would cause an increase in impeller tempera. ture rise.

However, going from Impellers $C$ to $B$, there is actually a slight decrease in impeller temperature rise. This is probably due to a global impeller separation somewhere between an area ratio of 2.55 and 2.748 as discussed previously. An impeller separation would cause an increase in impeller losses and therefore an increased impeller exit mixed-out meridional velocity. Therefore, for the same reasoning as above, the temperature would decrease. As the impe1ler area ratio is further increased, the temperature would once again increase provided the separated zone did not increase in area. This is precisely the behavior observed.

\section{Impeller Loading Diagrams}

The hub and shroud loading diagrams for the four impellers at $\mathrm{CL} / \mathrm{b}_{2}=0.08$ are shown in figure 18. The flow point chosen for comparison was design speed at 90 percent of design flow. This corresponds to the flow points surveyed at design speed. The loading diagrams were obtained from the MERIDL code (ref. 8) and are representative of the inviscid core flow. The exit conditions for MERIDL (total pressure, absolute swirl, and blockage) were obtained by assuming an ideal core flow which produced the same static pressure rise and aerodynamic blockage as was obtained from the experiment. The ideal relative velocity at the exit of the impeller was calculated from the measured exit static pressure and the ideal relative total pressure. The ideal relative flow angle was calculated by assuming that the slip velocity of the inviscid core was the same as that for the mixed-out state at impeller exit as described under data reduction. tion. The impeller exit aerodynamic blockage was then obtained from onedimensional continuity. The MERIDL code was modified to accept an input aero. dynamic blockage by reducing the tangential spacing between the blades by a blockage factor which was assumed to varly linearly between the leading and tralling edges. No total pressure loss was assumed for the core flow.

The impeller exit blockages calculated for the four impellers varied from 60.7 percent for Impeller $A$ to 49.7 percent for Impeller $D$. The calculated exit ideal relative critical velocity ratios varied from 0.570 for Impeller $A$ 
to 0.591 for Impeller $D$. The shroud static pressures from leading to trafling edge calculated by MERIOL using this method agreed with the experimental values everywhere within 3 percent.

Although these blockages seem high, they are typical for fully developed flow at impeller exit. For example, for a fully developed a flow with a power law velocity profile exponent of $1 / 2$ (shape factor $=2$ ) in both axial and tangential directions, the blockage would be 55.6 percent. This would correspond to a nearly separated flow.

If impeller separation did not occur, it would be expected that the impeller deceleration would increase uniformly as the impeller area ratio is increased. The loading dlagrams for the shroud show that this is not the case for this impeller. The diagrams show that a limiting value of deceleration is reached. For this impeller configuration, the limiting velocity ratio along the midpitch line at the shroud $\left(W_{m i n} / W_{1 t}\right)$ is reached for Impeller $B$ at a value of 0.64 . The shroud loading diagrams seem to indicate that global impeller separation does not occur for Impellers $D$ and $C$, possibly occurs for Impeller $B$ and probably occurs for Impeller $A$ since the minimum velocity attained decreases from Impellers $D$ to $B$ then increases for Impeller $A$. The trend is somewhat the same for the hub loading diagram but the minimum midpitch velocity for Impellers $B$ and $A$ are about the same. The minimum velocity ratios attained would seem to imply that calculations that yield lower values of the midpitch velocity ratio may have conditions at exit that are too optimistic. obviously, the values of minimum velocity ratio quoted for this impeller may not be generally applicable and confirmation of some limiting ratio would require analysis of a range of impellers with different geometries and design conditions.

In order to determine how much the minimum velocity change was affected by the increased viscous effects and separation as area ratio increased, the MERIDL code was run twice more for each area ratio. For the first variation the intent was to determine how the minimum velocity varied only as a result of the area ratio change from Impellers $D$ to $A$. The blockage calculated for Impeller $D$ was used with the slip velocity determined experimentally for Impellers $C, B$, and $A$ to establish the downstream input conditions for the MERIDL code. The second variation was to estimate the increase in viscous losses due to increased diffusion but eliminate the effects of separation. A centrifugal compressor design code which utilized internal boundary layer calculations to estimate viscous losses was used without a separation criterion (the shape factor used to indicate separation was set to a high value) to establish the slope in total temperature and static pressure rise from Impe 1lers $D$ to $A$. The predictions were normalized with the experimental values obtained for Impeller D (the predicted values were close to the experimental values for Impeller $D$ ). MERIDL exit conditions for Impellers $C, B$, and $A$ were then obtained from the adjusted total temperature and static pressure. These two variations as well as the results obtained with the test data are shown in figure 19 as curves of minimum midpitch velocity at the shroud divided by the inlet midpitch velocity. This ratio should be representative of the amount of global diffusion attained in the impeller passages. As expected the trend obtained with the blockage held constant shows the velocity ratio continually decreasing with increasing area ratio. The trend obtained with the total temperature and static pressure estimated with the design code for Impellers $B$ and $A$ also shows a continually decreasing velocity ratio but not as fast as for the constant blockage case. The differing levels of minimum velocity ratio 
for these two variations gives an idea of the effect that the increased viscous losses have on the diffusion attainable in the impeller. The third trend which was obtained from the actual data shows the velocity ratio decreasing to a minimum value for Impeller $B$ and then increasing for Impeller $A$. The deviation of these ratios from those calculated with the design code estimates indicates the possible effect of flow separation on the aerodynamic blockages calculated for Impellers $B$ and $A$.

\section{SUMMARY OF RESULTS}

This paper has presented the results of an experimental study of the affect of equivalent area ratio on impeller performance. Surveys of total pressure, total temperature, and flow angle were taken downstream of a backswept impeller operating with a vaneless diffuser. The data indicate the following:

1. For the impeller tested the equivalent pressure recovery coefficient and impeller efficiency reached maximum values at area ratios of 2.748 and 2.55 , respectively.

2. The impeller efficiency decreases about 0.4 point for every 1 percent increase in exit clearance. The clearance effect on impeller efficiency is relatively insensitive to area ratio changes.

3. The efficiency measured at the survey station indicates the aero. dynamic losses are strongly dependent upon clearance for the next to smallest area ratio tested. The clearance effect on these losses at the other area ratios is small.

4. Application of a quasi-three-dimensional computer code to the impe1lers using the experimentally determined exit conditions determined that the minimum shroud midpitch velocity was attained at the next to highest area ratio tested.

5. The experimental data indicate that the highest area ratio impeller tested experienced a global separation of the impeller. 


\section{APPENDIX}

\section{AVERAGING PROCEDURE FOR SURVEY QUANTITIES}

The purpose of the integrated average values was to obtain single quantities that represented the energy transfer and inefficiency associated with the compression process. A procedure is described below which restricts the quantities averaged to extensive properties only. Other quantities are derived from these two averages so that the resultant averaged velocity triangle is representative of the energy transferred to the fluid and continuity. Overall mass flow rate was calculated by determining the mass flux, $\rho V \cos \alpha$, at each spanwise location. This quantity was set equal to zero at the walls and a cubic spline used to integrate the fluxes across the span to obtain the mass flow rate. Total enthalpy and ideal total enthalpy (obtained from the measured total pressure) were mass averaged in order to get overall quantities representative of the flow. Average total temperature was obtained from the average total enthalpy and average total pressure was obtained from the average ideal total enthalpy. Static pressure was assumed constant across the channel and was used with the averaged total pressure to calculate an average critical velocity ratio (see eq. (1-61) of ref.9). Average static density was calculated from the average critical velocity ratio, average total pressure, and average total temperature. With the known integrated mass flow rate, a flow angle consistent with continuity could be obtained. 


\section{REFERENCES}

1. Balje, 0.E.: "A Study On Design Criteria and Matching of Turbomachines; Part B - Compressor and Pump Performance and Matching of Turbocomponents." Journal Engineering for Power, Vol. 84, No. 1, Jan. 1962, pp. 103-114.

2. Rodgers, C.: "Specific Speed and Efficiency of Centrifugal Impellers," Performance Prediction of Centrifugal Pumps and Compressors, ASME, New York, 1980, pp. 191-200.

3. Mishina, $H$. and Nishida H.: "Effect of Relative Velocity Distribution on Efficiency and Exit Flow of Centrifugal Impellers," ASME Paper 83-G1-74, Mar. 1983.

4. Galvas, M.R.: "A Compressor Designed for the Energy Research and Development Agency Automotive Gas Turbine Program," NASA TM-X-71719, 1975.

5. Katsanis, T. and McNally, W.D.: "Fortran Program for Calculating Veloci.ties and Streamlines on a Blade-to-Blade Stream Surface of a Tandem Blade Turbomachine," NASA TN-D-5044, 1969.

6. Pampreen, R.C.: "Splitter-Bladed Centrifugal Compressor Impeller Designed for Automotive Gas Turbine Application," NASA CR-135237, 1977.

7. Klassen, H.A., Wood, J.R., and Schumann, L.F.: "Experimental Performance of a 16.10-Centimeter-7ip-Diameter Sweptback Centrifugal Compressor Designed for a 6:1 Pressure Ratio," NASA TM-X-3552, 1977.

8. Katsanis, T. and McNally, W.O.: "Revised Fortran Program for Calculating Velocities and Streamlines on the Hub-Shroud Midchannel Stream Surface of an Axial-, Radial-, or Mixed-Flow Turbomachine or Annular Duct: Part I User's Manual," NASA TN-D-8430, 1977.

9. Glassman, A.J.: "Turbine Design and Application," NASA SP-290, Vol. I, 1972 . 
TABLE I. - IMPELLER CONFIGURATIONS

\begin{tabular}{|c|c|c|c|c|}
\hline Impeller & $\mathrm{b}_{2} / r_{2}$ & $\begin{array}{l}\text { AR IMP } \\
\text { design } \\
\text { point }\end{array}$ & Clearance & $\begin{array}{l}\mathrm{CL} / \mathrm{b}_{2} \\
\text { design } \\
\text { speed }\end{array}$ \\
\hline A & 0.0728 & 2.945 & $\begin{array}{l}\text { Smal } 1 \\
\text { Medi um } \\
\text { Large }\end{array}$ & $\begin{array}{r}0.023 \\
.057 \\
.090\end{array}$ \\
\hline B & .0679 & 2.748 & $\begin{array}{l}\text { Smal } 1 \\
\text { Medium } \\
\text { Large }\end{array}$ & $\begin{array}{l}.047 \\
.083 \\
.115\end{array}$ \\
\hline C & .0630 & 2.550 & $\begin{array}{l}\text { Small } \\
\text { Medium } \\
\text { Large }\end{array}$ & $\begin{array}{l}.054 \\
.093 \\
.128\end{array}$ \\
\hline D & .0574 & 2.322 & $\begin{array}{l}\text { Smal1 } \\
\text { Medium } \\
\text { Large }\end{array}$ & $\begin{array}{l}.072 \\
.115 \\
.153\end{array}$ \\
\hline
\end{tabular}




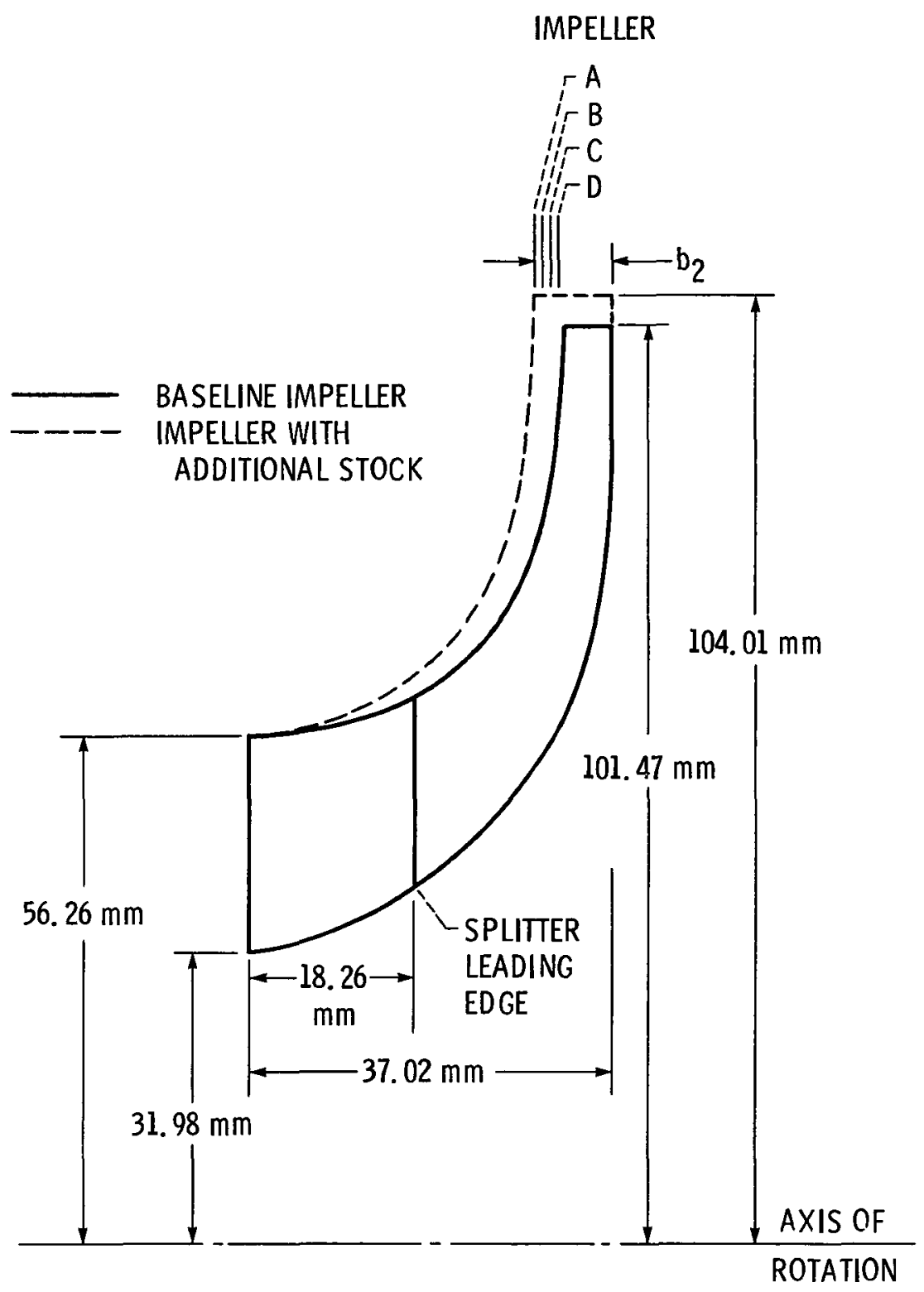

Figure 1. - Impeller configurations and geometry. 


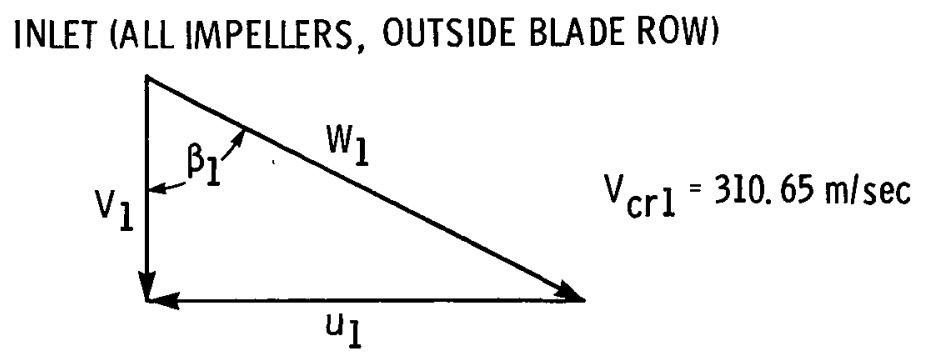

$\begin{array}{lcccccc} & \mathrm{u}_{1} / V_{c r l} & V_{1} / V_{c r l} & W_{1} / W_{c r l} & \beta_{1} & P_{1}^{\prime} / P_{S T D} & T_{1}^{\prime} / T_{S T D} \\ \text { HUB } & 0.494 & 0.398 & 0.597 & 51.11 & 1.0 & 1.0 \\ \text { MEAN } & .730 & .487 & .827 & 56.27 & 1.0 & 1.0 \\ \text { TIP } & .872 & .562 & .977 & 57.21 & 1.0 & 1.0\end{array}$

- EXIT (MEAN, OUTSIDE BLADE ROW)

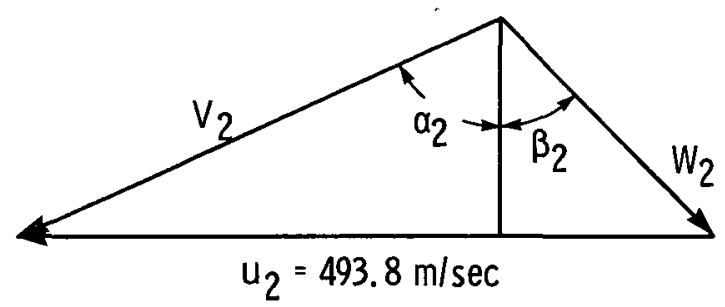

$\begin{array}{cccccccc}\text { IMPELLER } & \mathrm{u}_{2} / V_{\mathrm{cr} 2} & \mathrm{~V}_{2} / V_{\mathrm{cr} 2} & \mathrm{~W}_{2} / \mathrm{W}_{\mathrm{cr} 2} & \alpha_{2} & \beta_{2} & \mathrm{P}_{2}^{\prime} / \mathrm{P}_{1}^{\prime} & \mathrm{T}_{2}^{\prime} / T_{1}^{\prime} \\ \mathrm{D} & 1.239 & 0.989 & 0.455 & 75.63 & 48.83 & 5.162 & 1.683 \\ \mathrm{C} & 1.236 & .990 & .427 & 77.13 & 50.84 & 5.269 & 1.690 \\ \mathrm{~B} & 1.234 & .994 & .404 & 78.28 & 52.20 & 5.385 & 1.697 \\ \mathrm{~A} & 1.231 & .998 & .383 & 79.25 & 53.32 & 5.501 & 1.704\end{array}$

Figure 2. - Design point impeller velocity diagrams at design mass flow rate. 


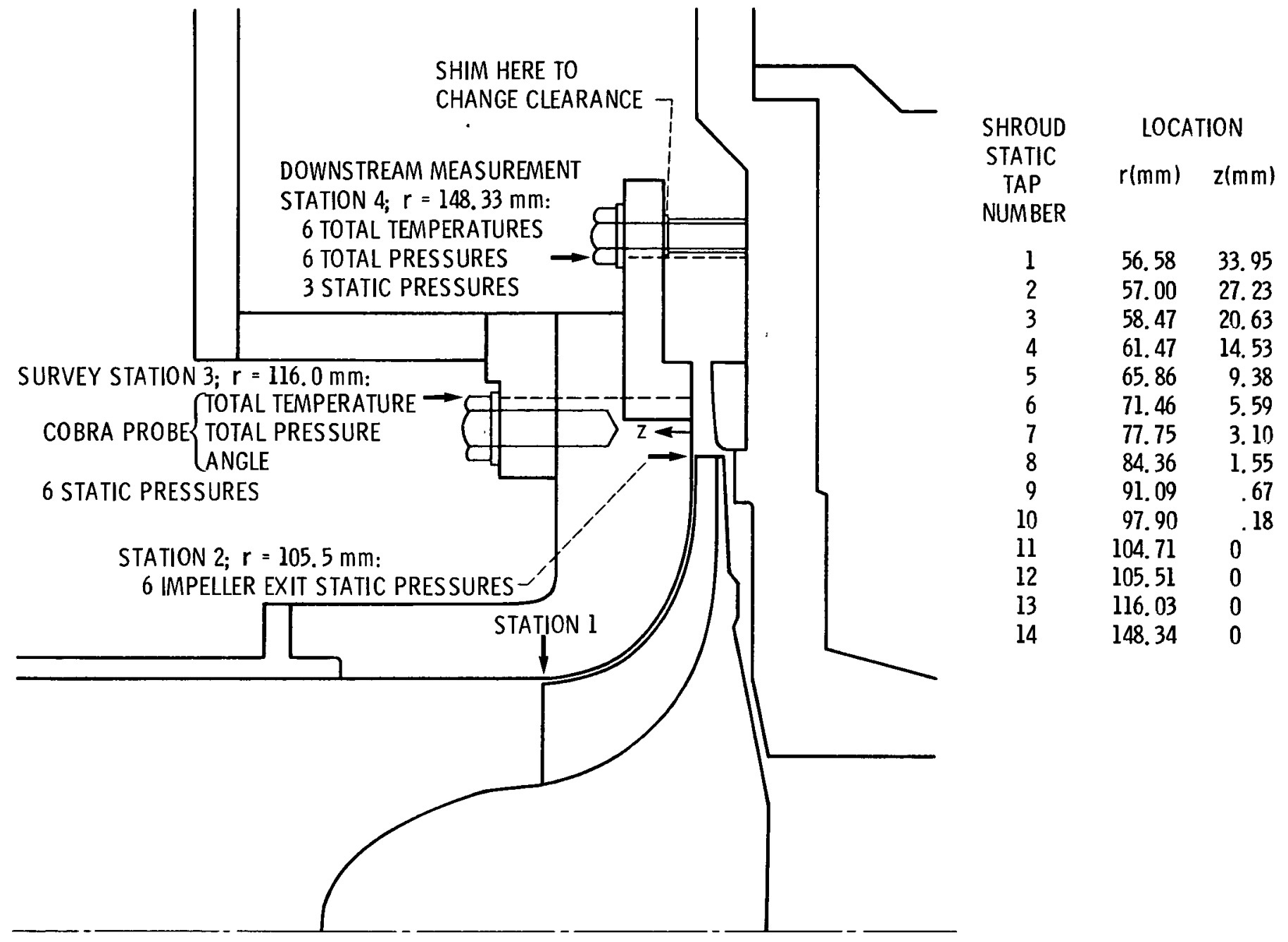

Figure 3. - Compressor flow path and instrumentation stations. 


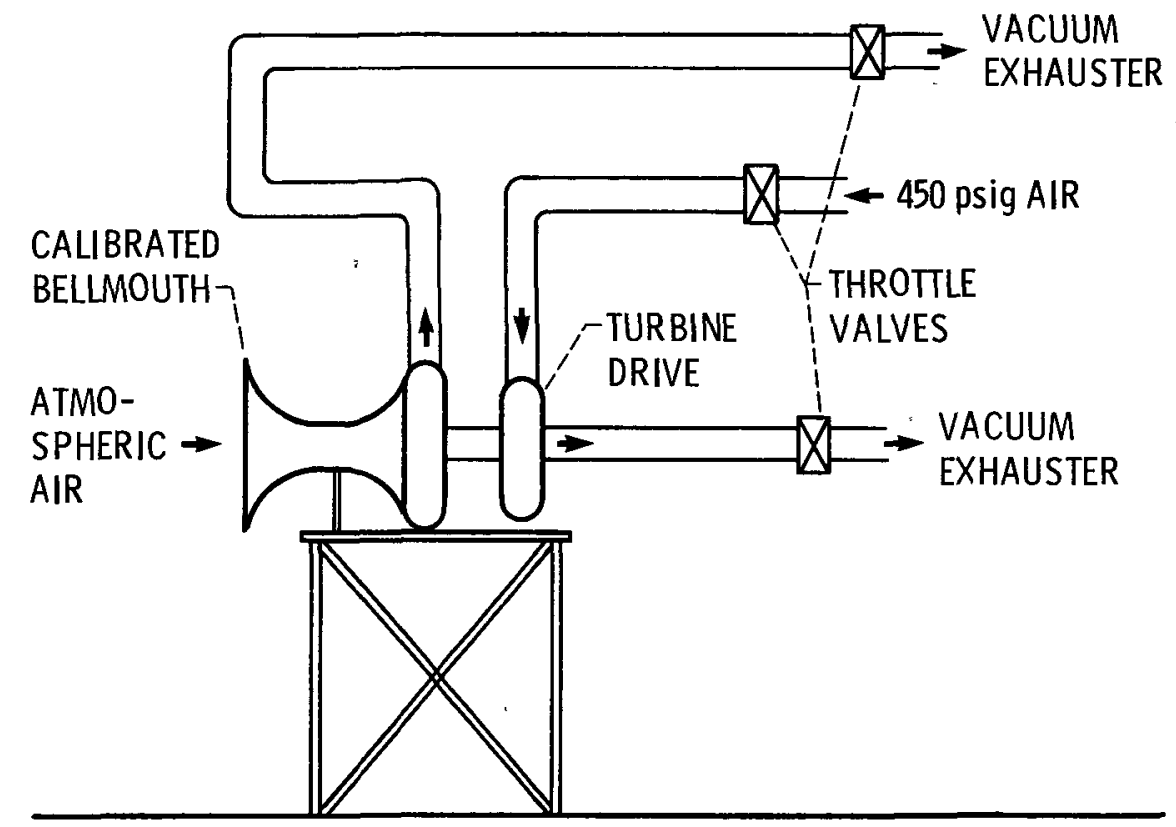

Figure 4. - Small centrifugal compressor facility.

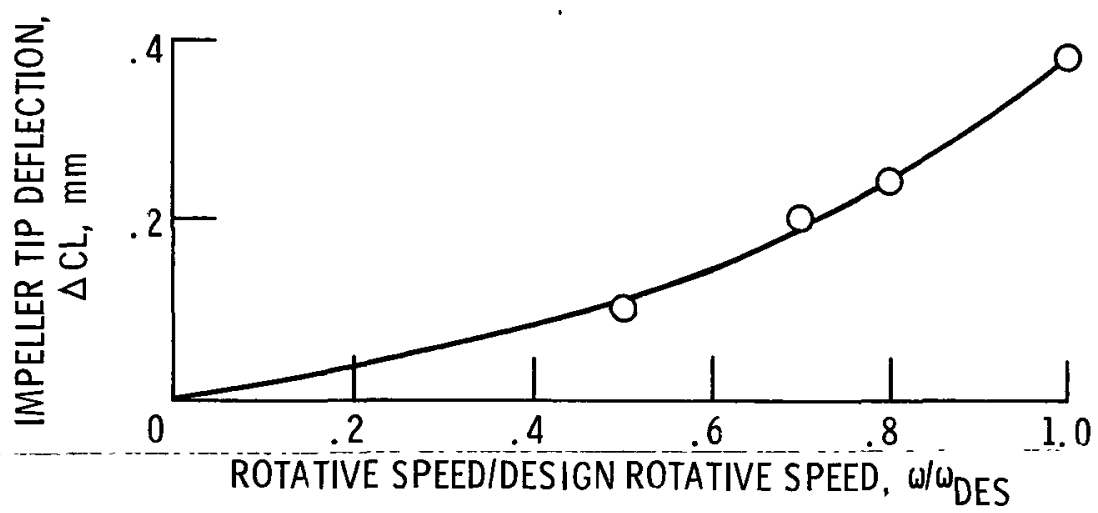

Figure 5. - Impeller tip deflection versus rotative speed. 


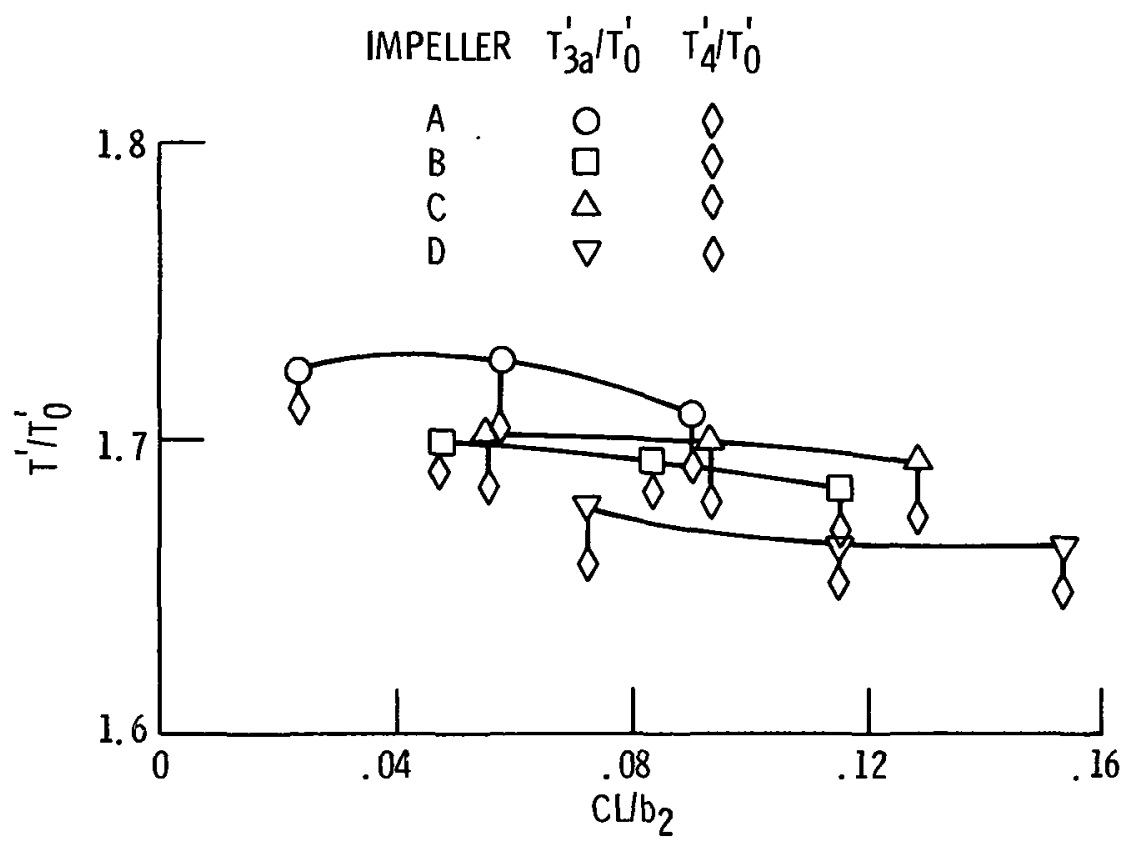

Figure 6. - Impeller temperature rise versus clearance. 100 percent design speed; $\dot{\mathrm{m}} / \dot{\mathrm{m}}_{\mathrm{DES}}=0.90$. 


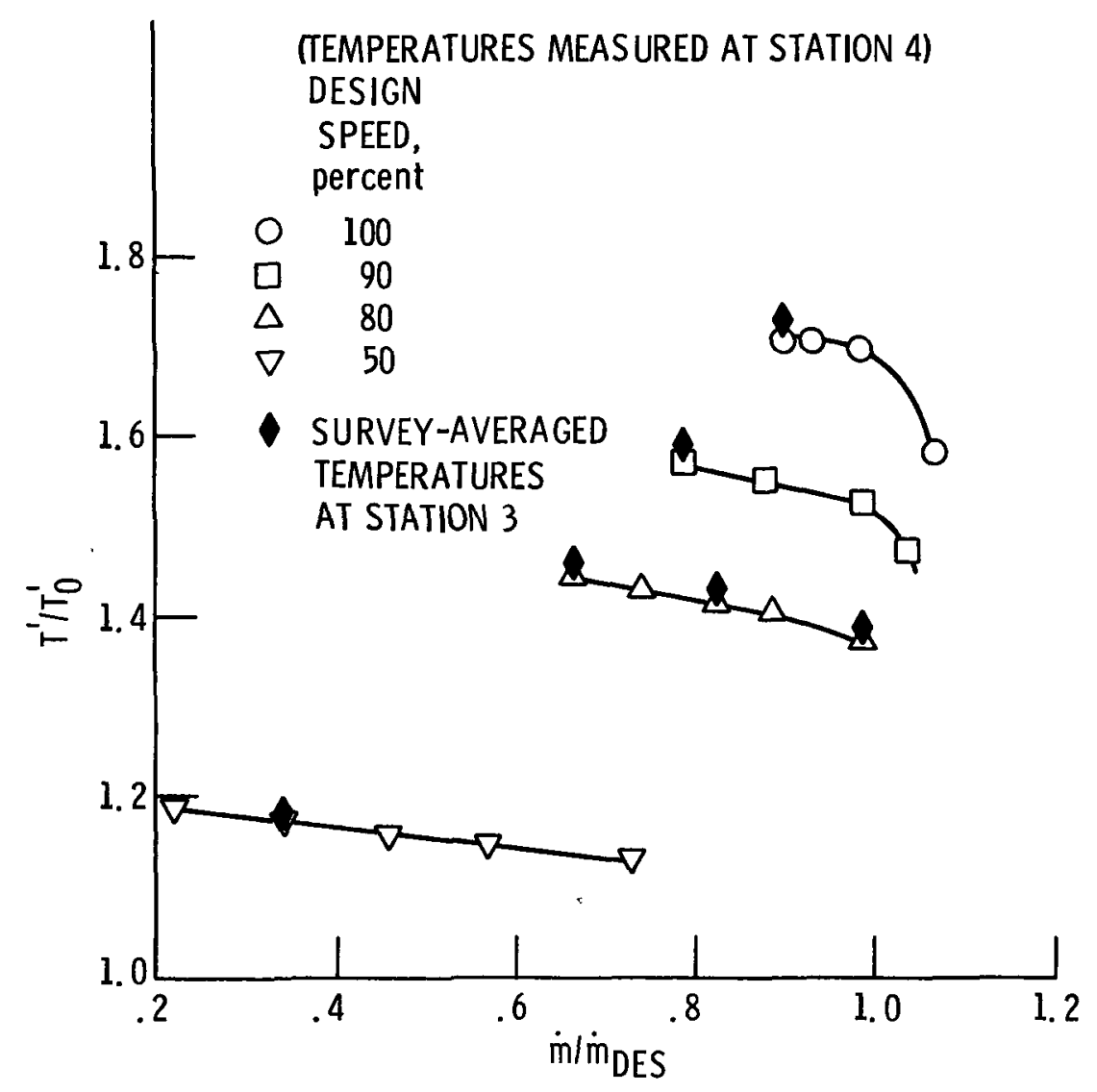

(a) Temperature ratio.

Figure 7. - Performance characteristics for impeller $A$ $\left(\mathrm{CUb} \mathrm{b}_{2}=0.023\right)$. 


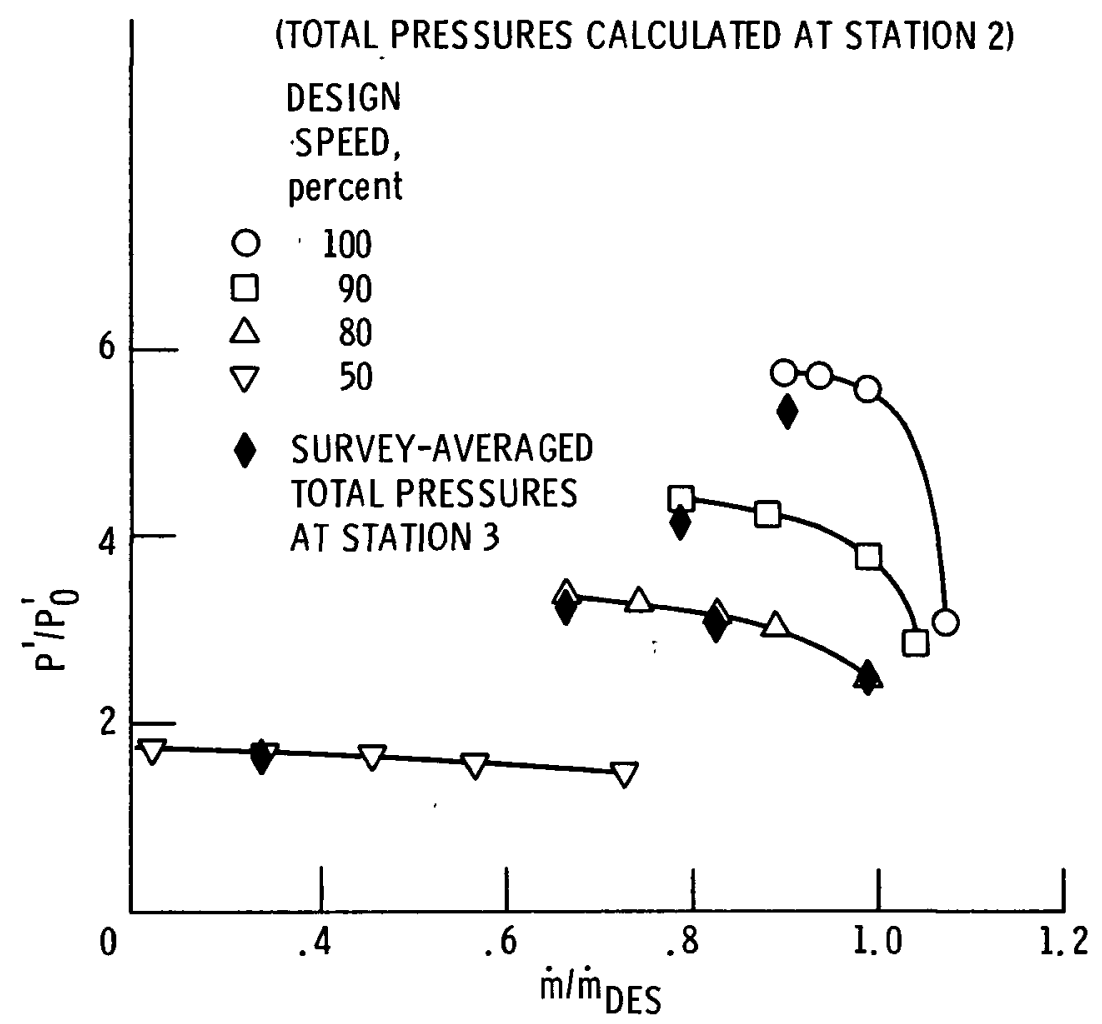

(b) Total pressure ratio.

Figure 7. - Continued. 


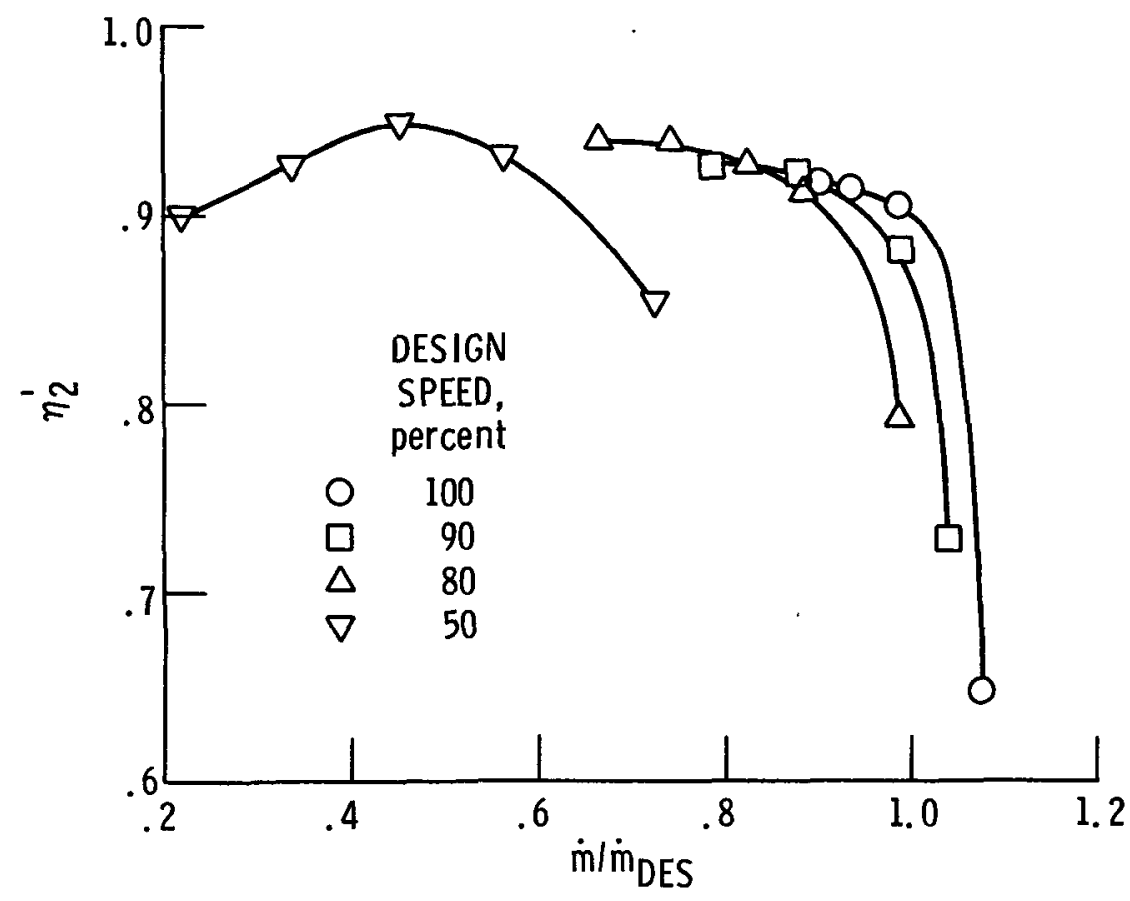

(c) Total efficiency.

Figure 7. - Concluded.

- SMALL CLEARANCE

口 MEDIUM CLEARANCE

$\triangle$ LARGE CLEARANCE

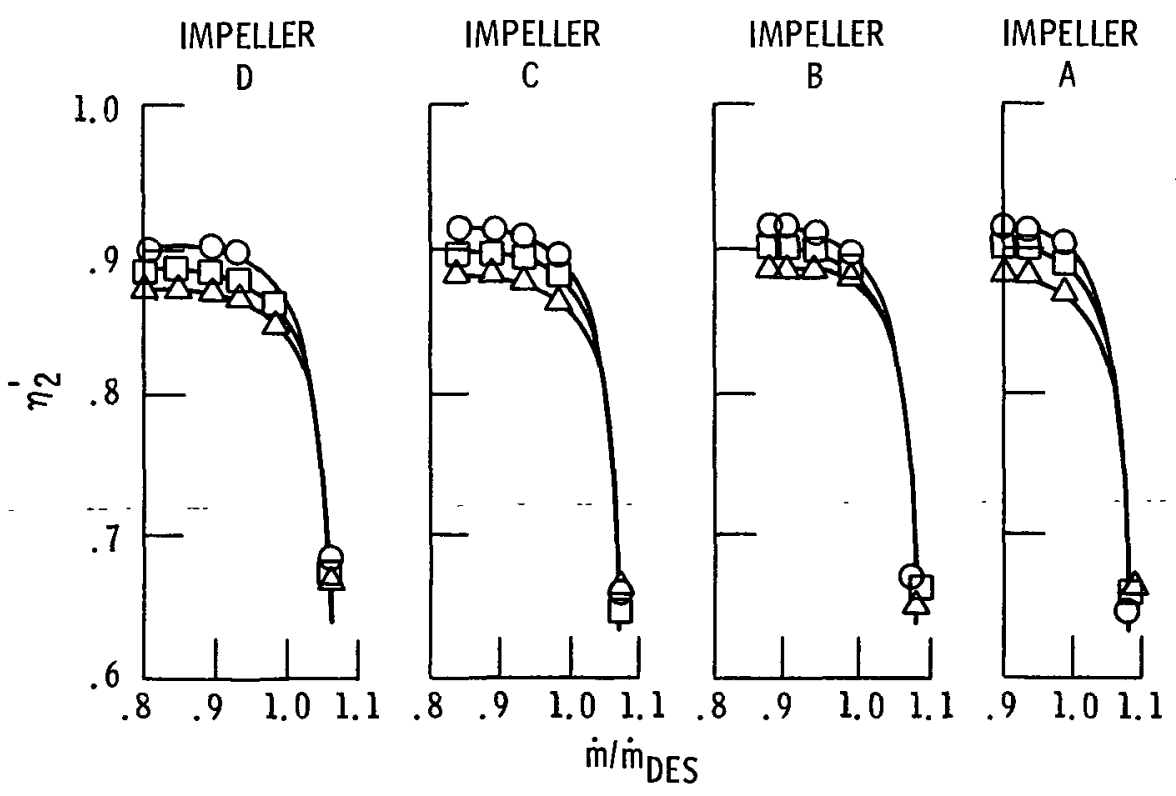

Figure 8. - Impeller total efficiency versus mass flow at design speed. 


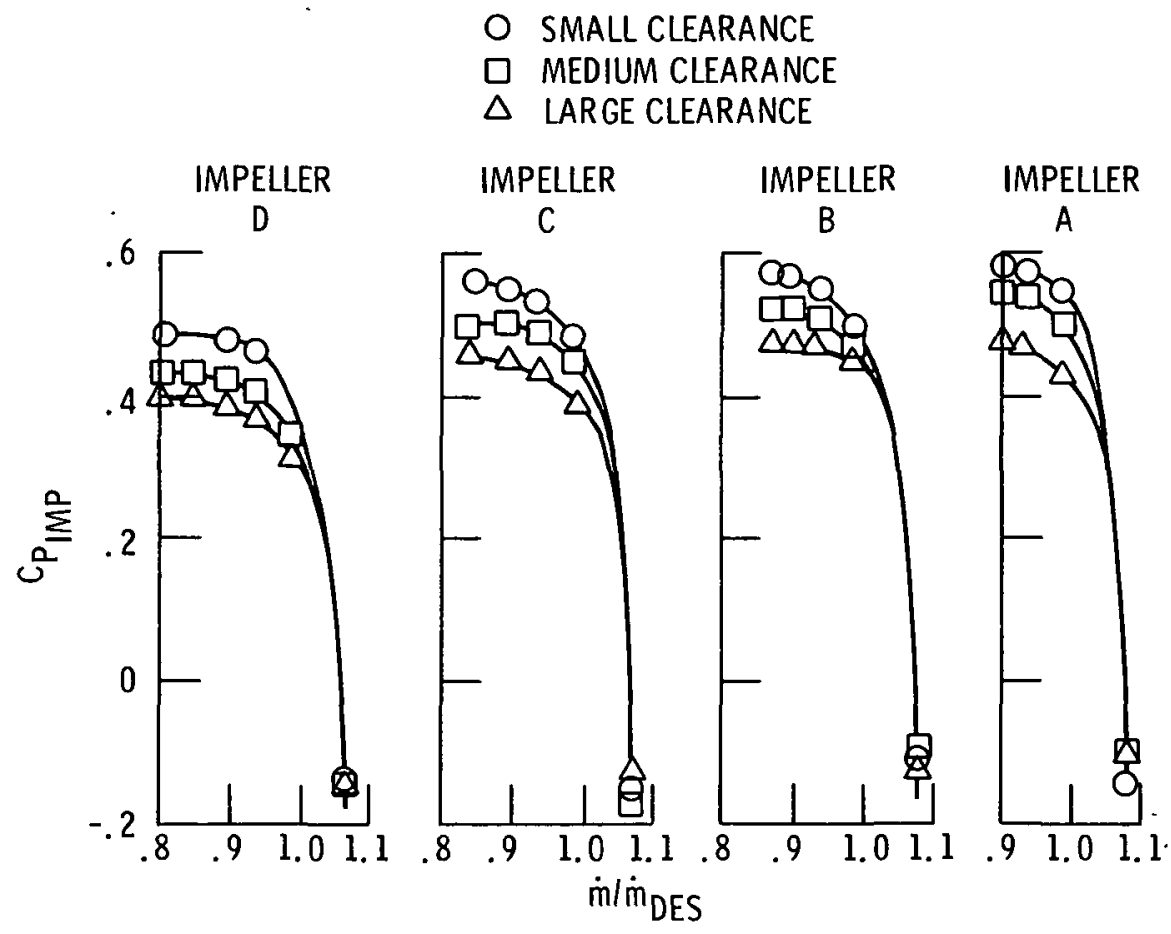

Figure 9. - Impeller equivalent static pressure coefficient versus mass flow at design speed. 


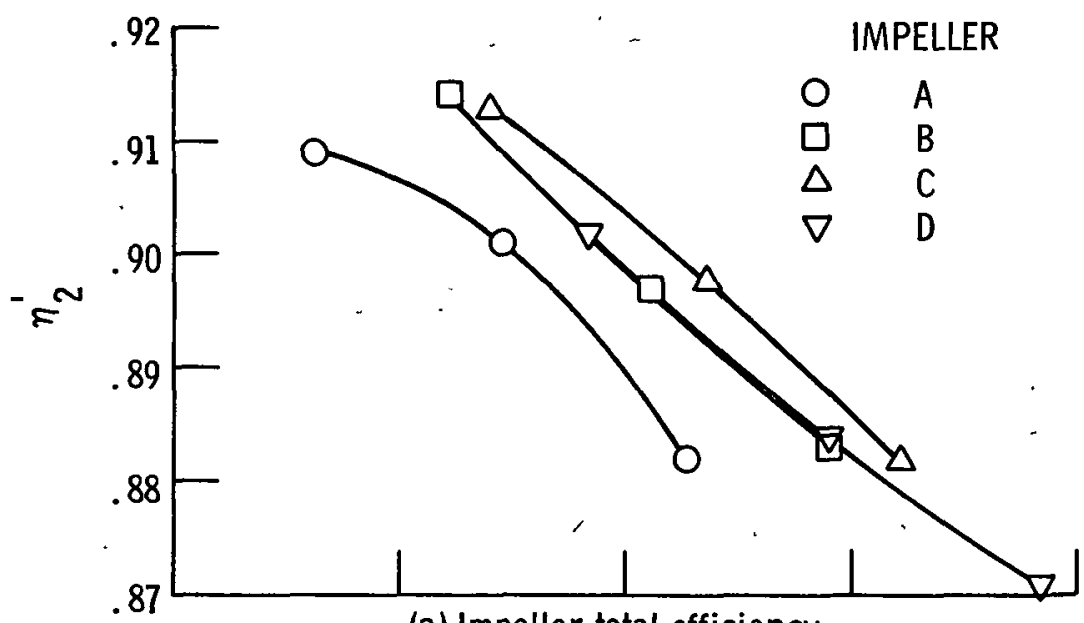

(a) Impeller total efficiency.

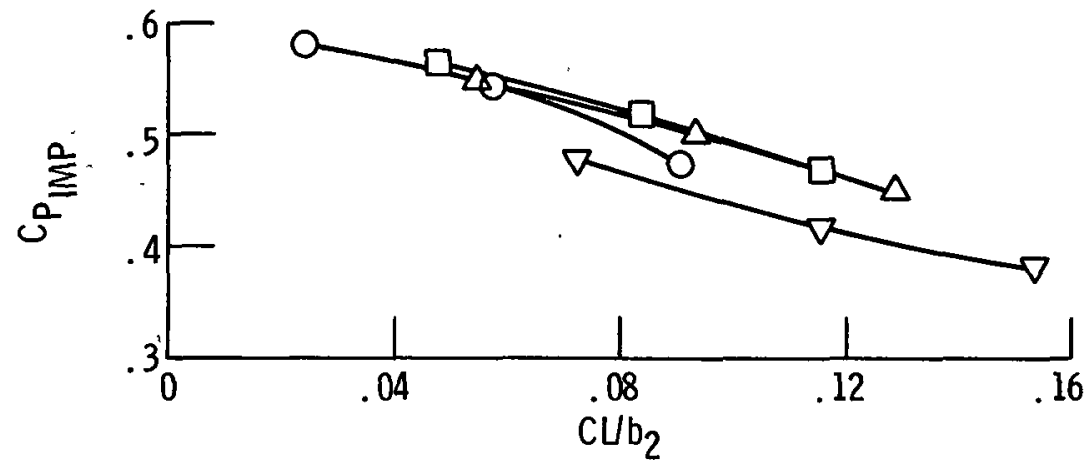

(b) Impeller equivalent static pressure recovery coefficient.

Figure 10. - Impeller performance characteristics versus clearance for design speed and $\dot{\mathrm{m}} / \dot{\mathrm{m}}_{\mathrm{DES}}=0.90$. 


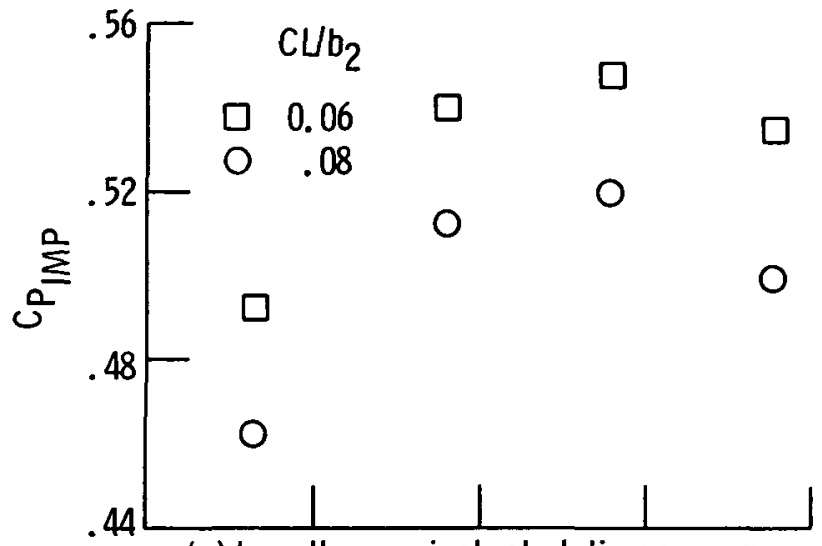

(a) Impeller equivalent static pressure recovery coefficient.

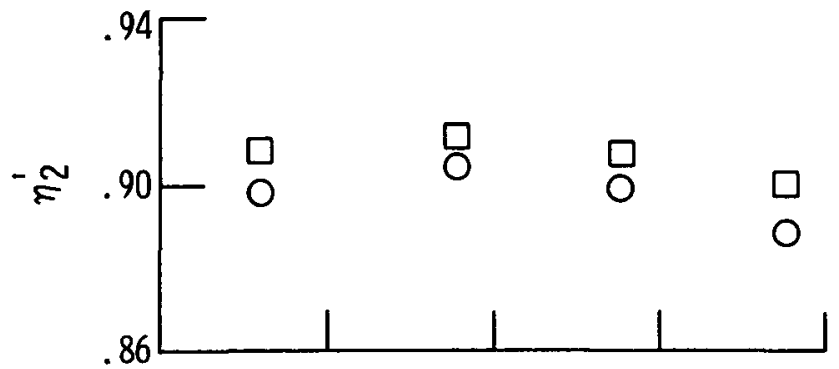

(b) Calculated impeller aerodynamic efficiency.

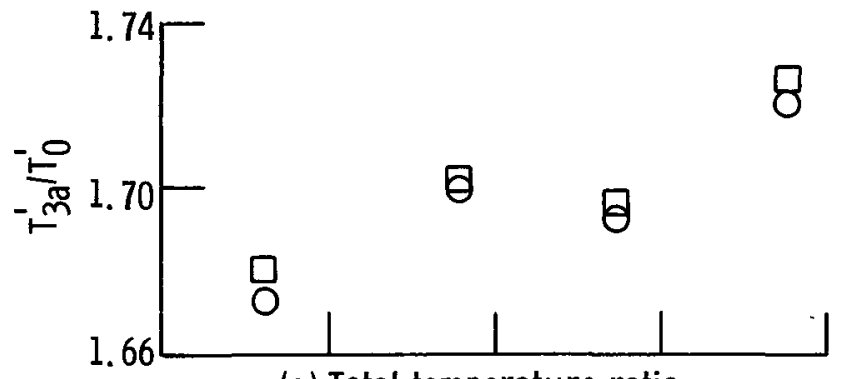

(c) Total temperature ratio.

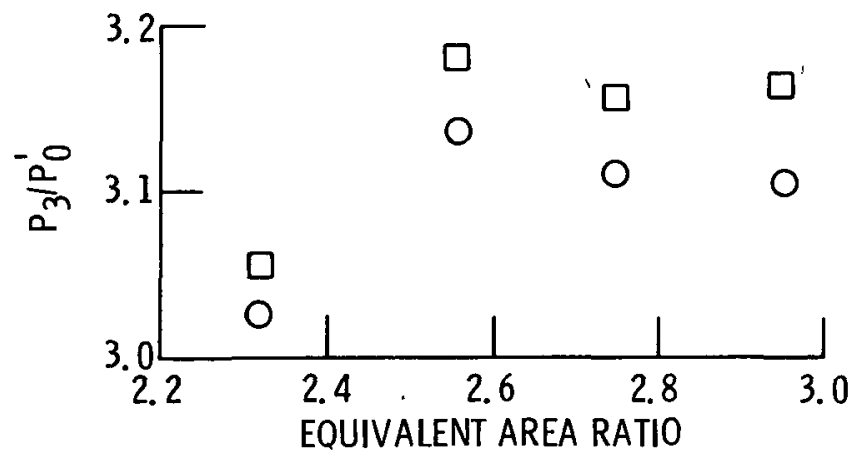

(d) Static pressure ratio.

Figure 11. - Performance parameters for constant percent clearance versus impeller equivalent area ratio. 

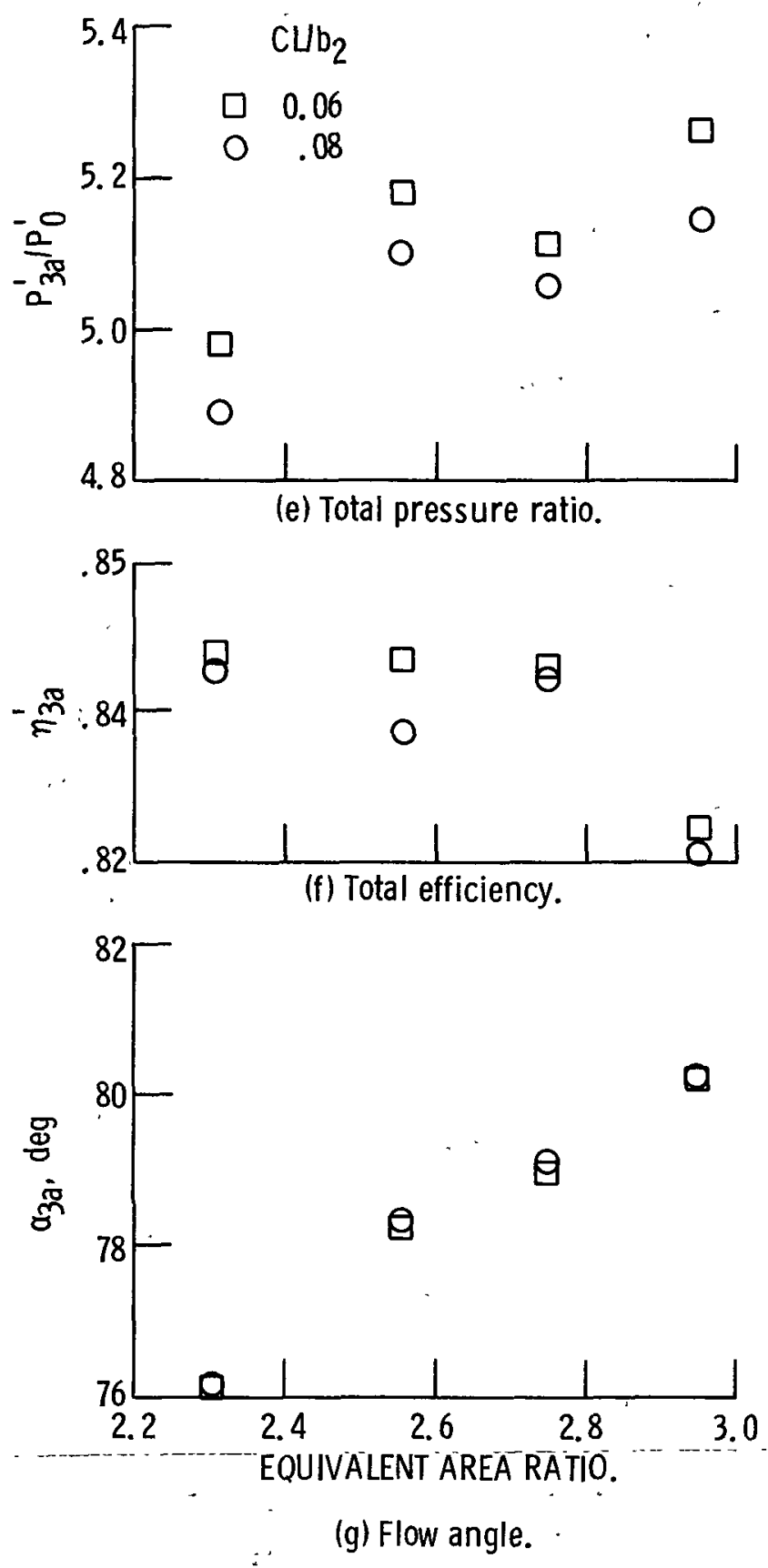

Figure 1l. - Concluded. 

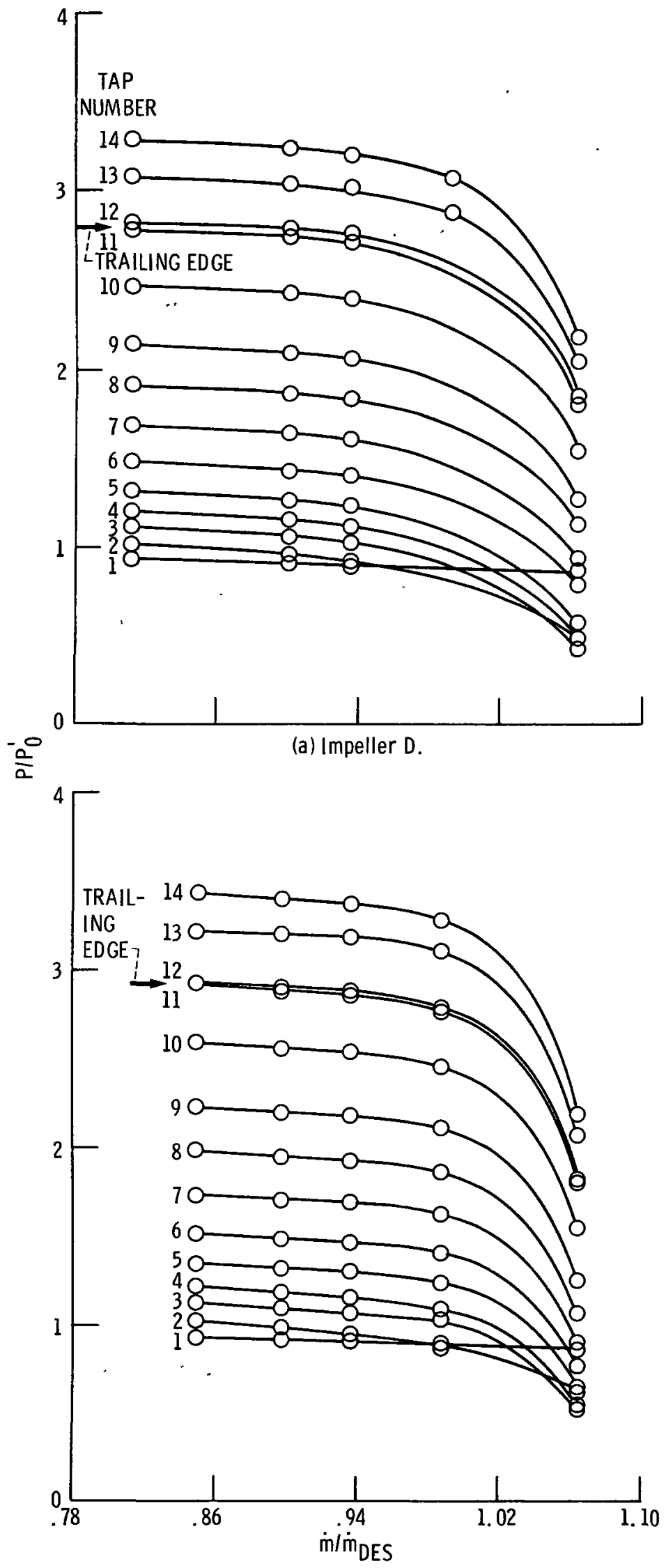

(b) Impeller C.

Figure 12. - Shroud static pressure distribution for design speed and small clearance. 

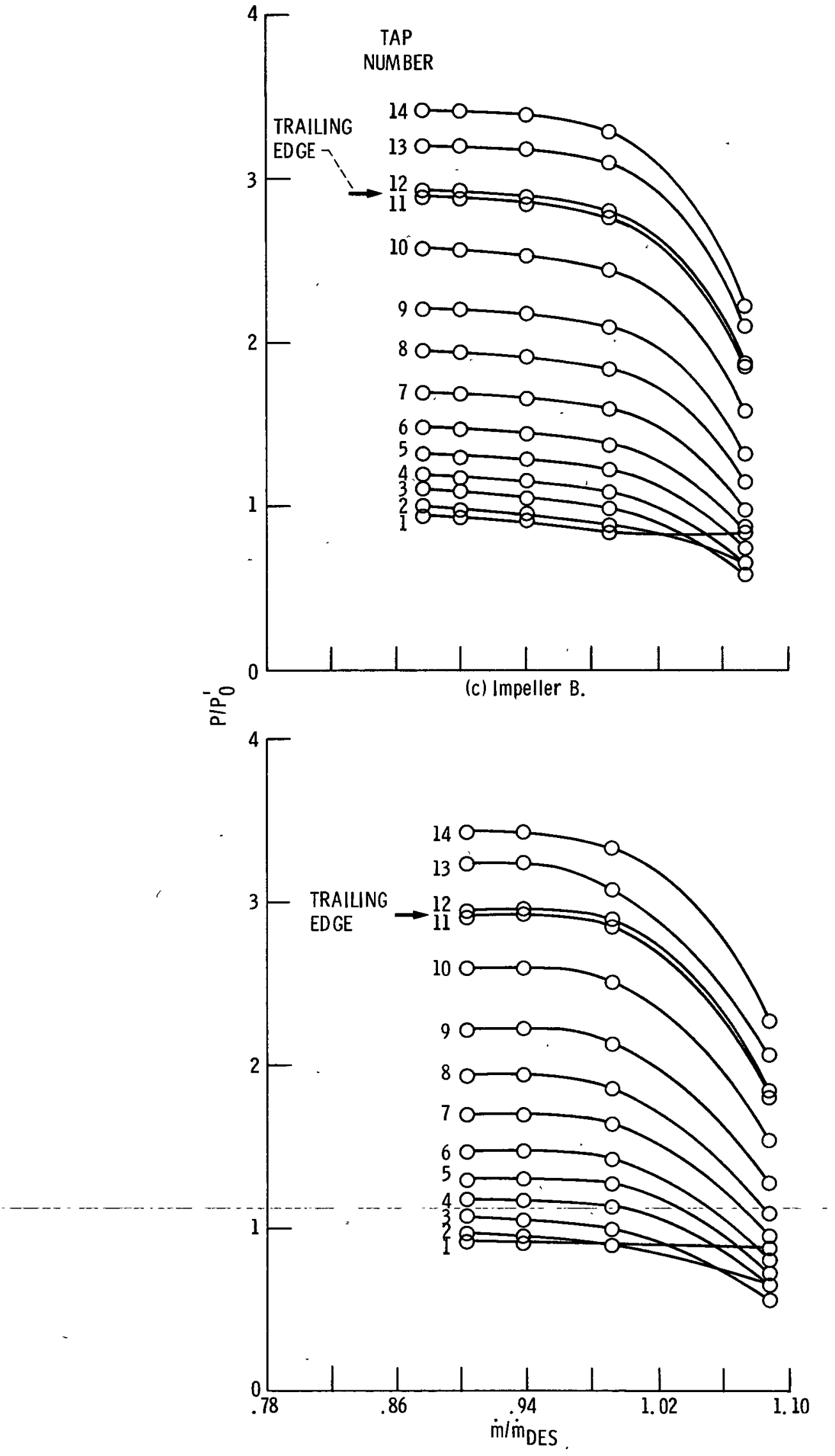

(d) Impeller A.

Figure 12. - Concluded. 

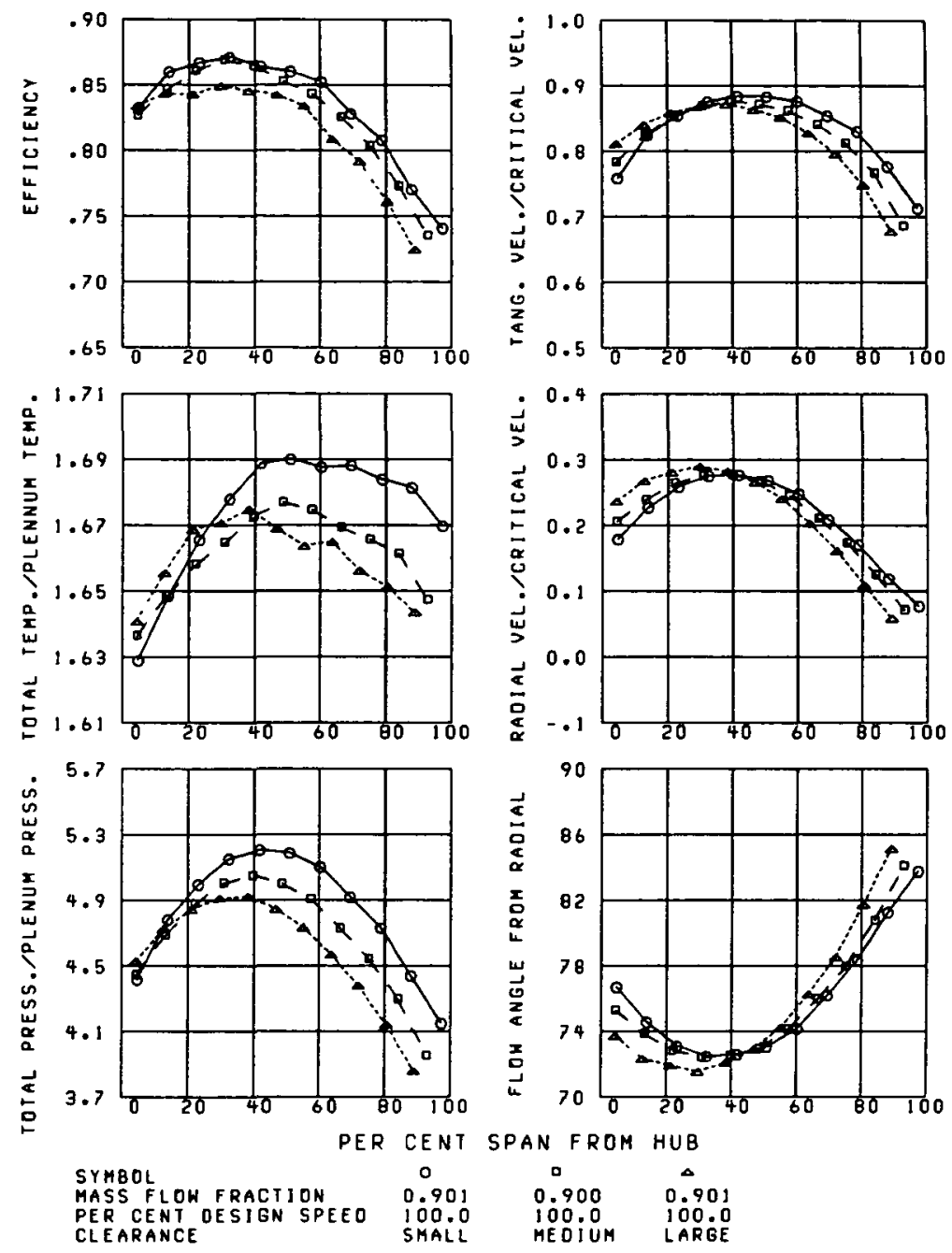

Figure 13. - Clearance comparison - 100 percent speed impeller $D$. 

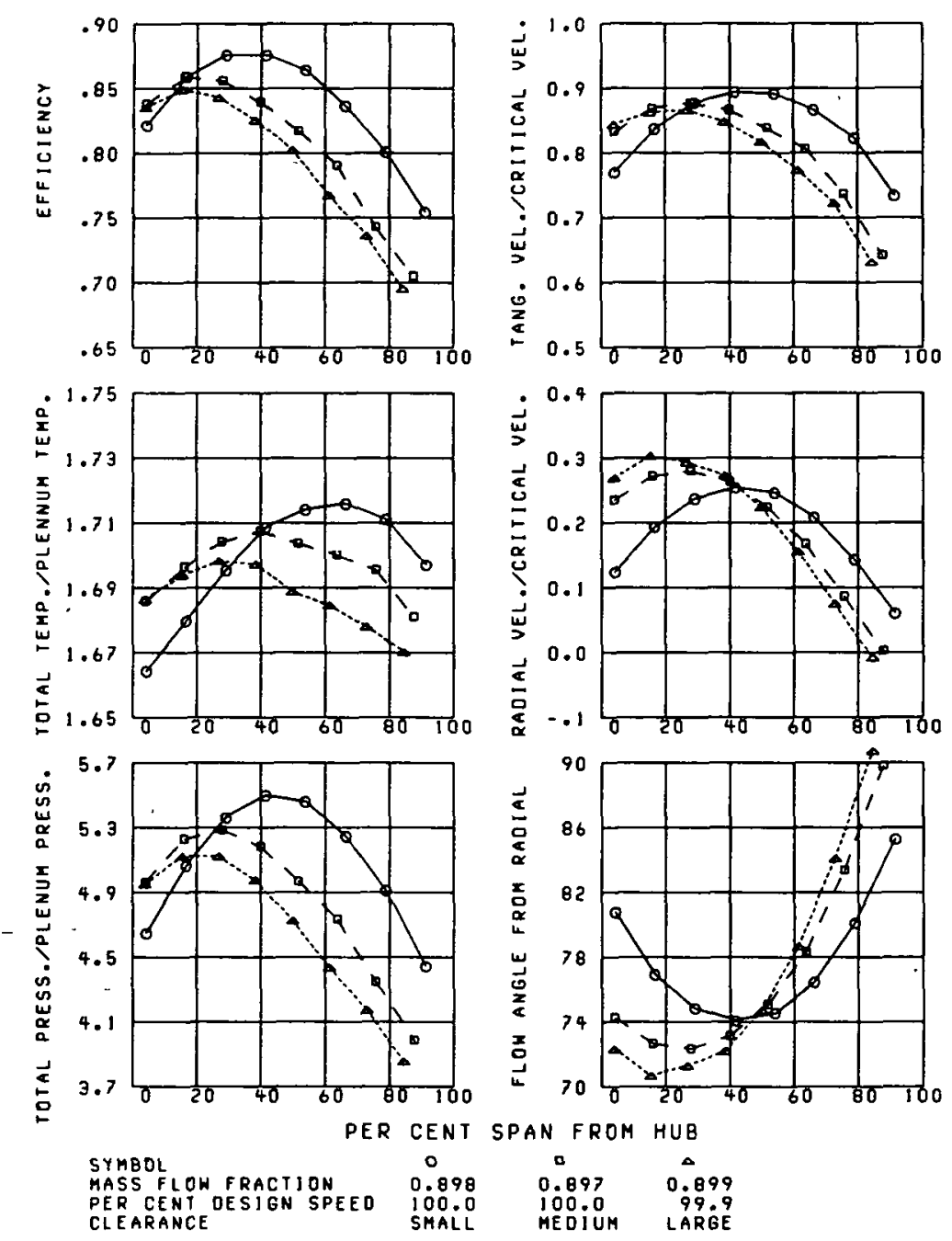

Figure 14. - Clearance comparison - 100 percent speed impeller $\mathrm{C}$. 

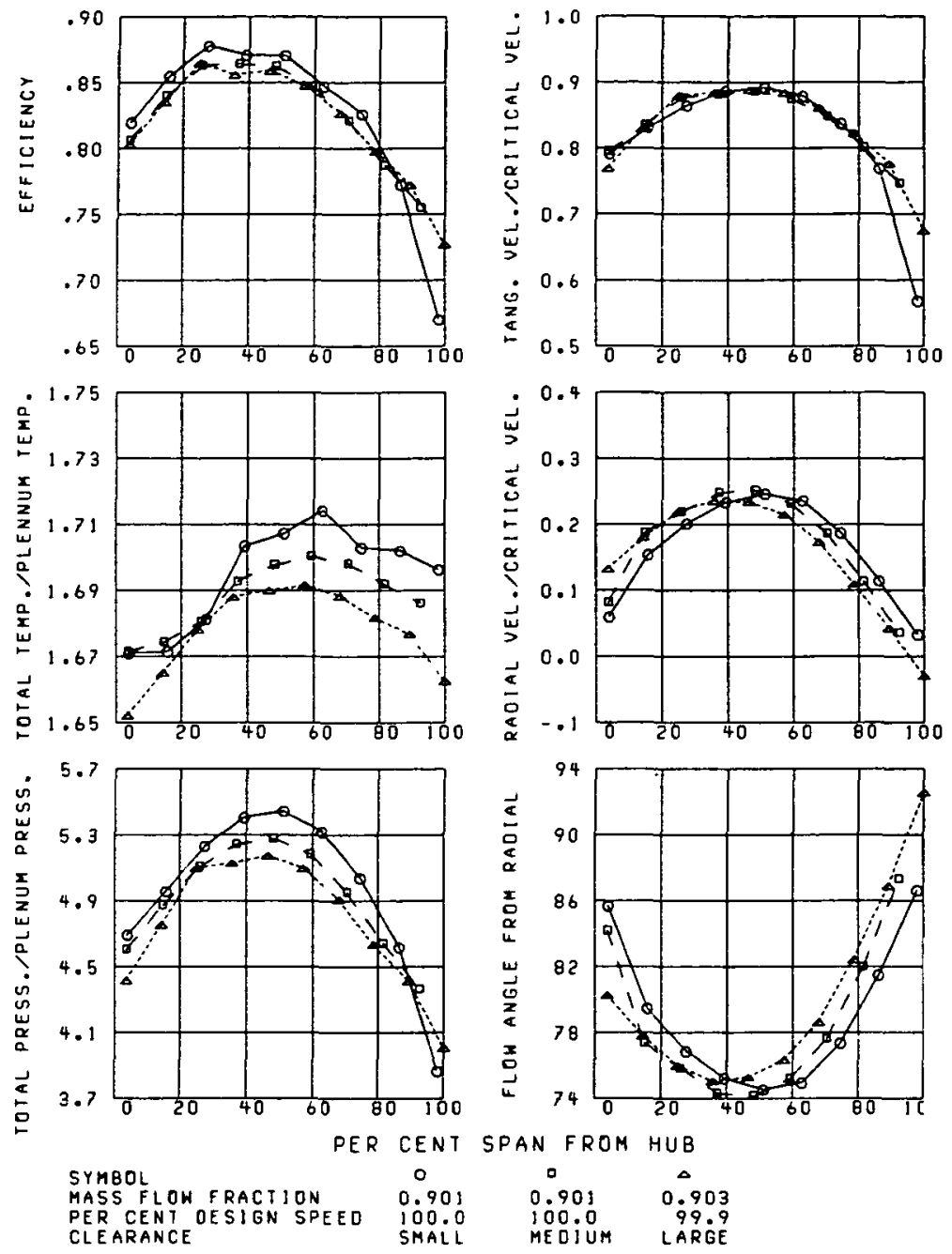

Figure 15. - Clearance comparison - 100 percent speed impeller $\mathrm{B}$. 

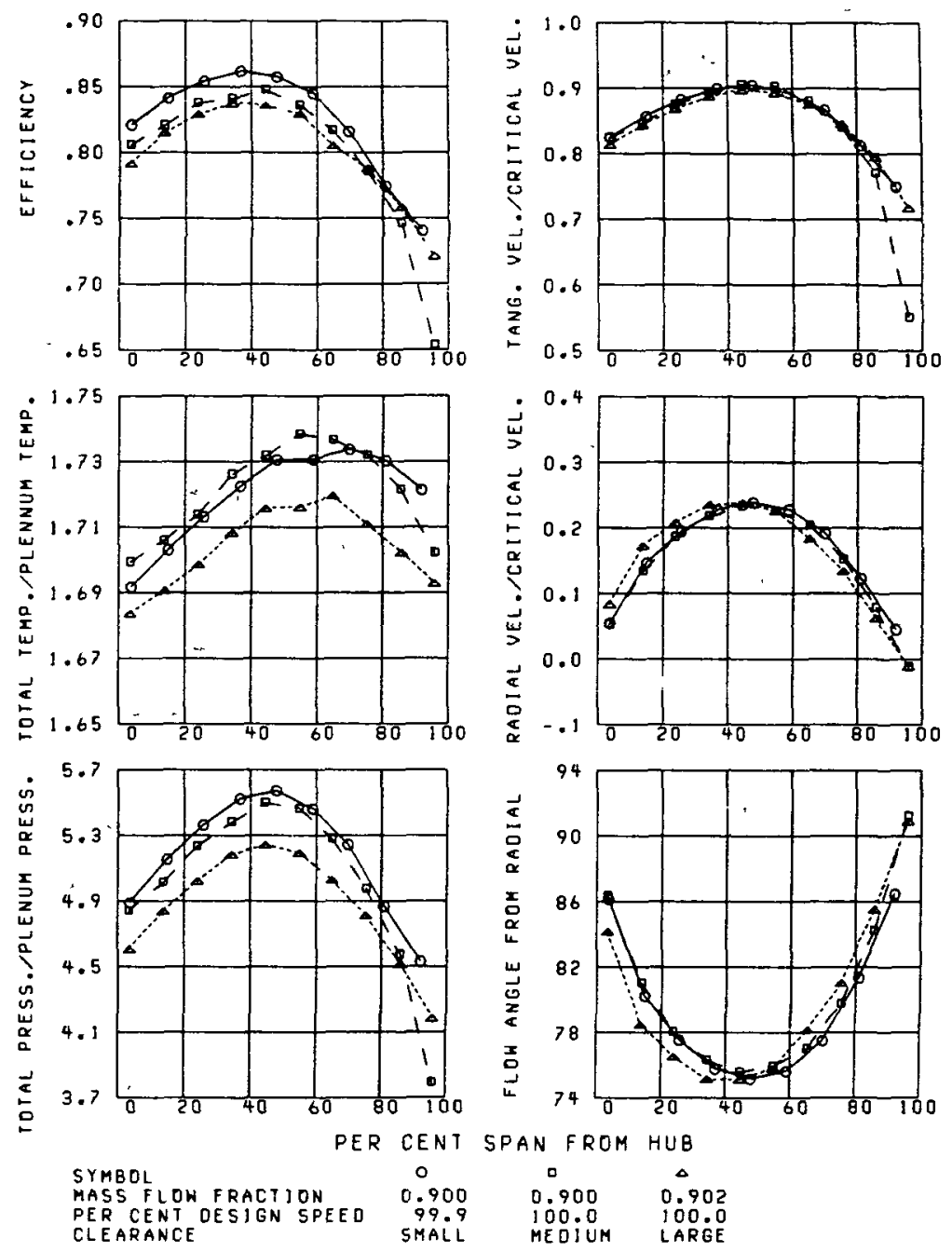

Figure 16. - Clearance comparison - 100 percent speed impeller $A$. 
ORIGINAL PAGE IS
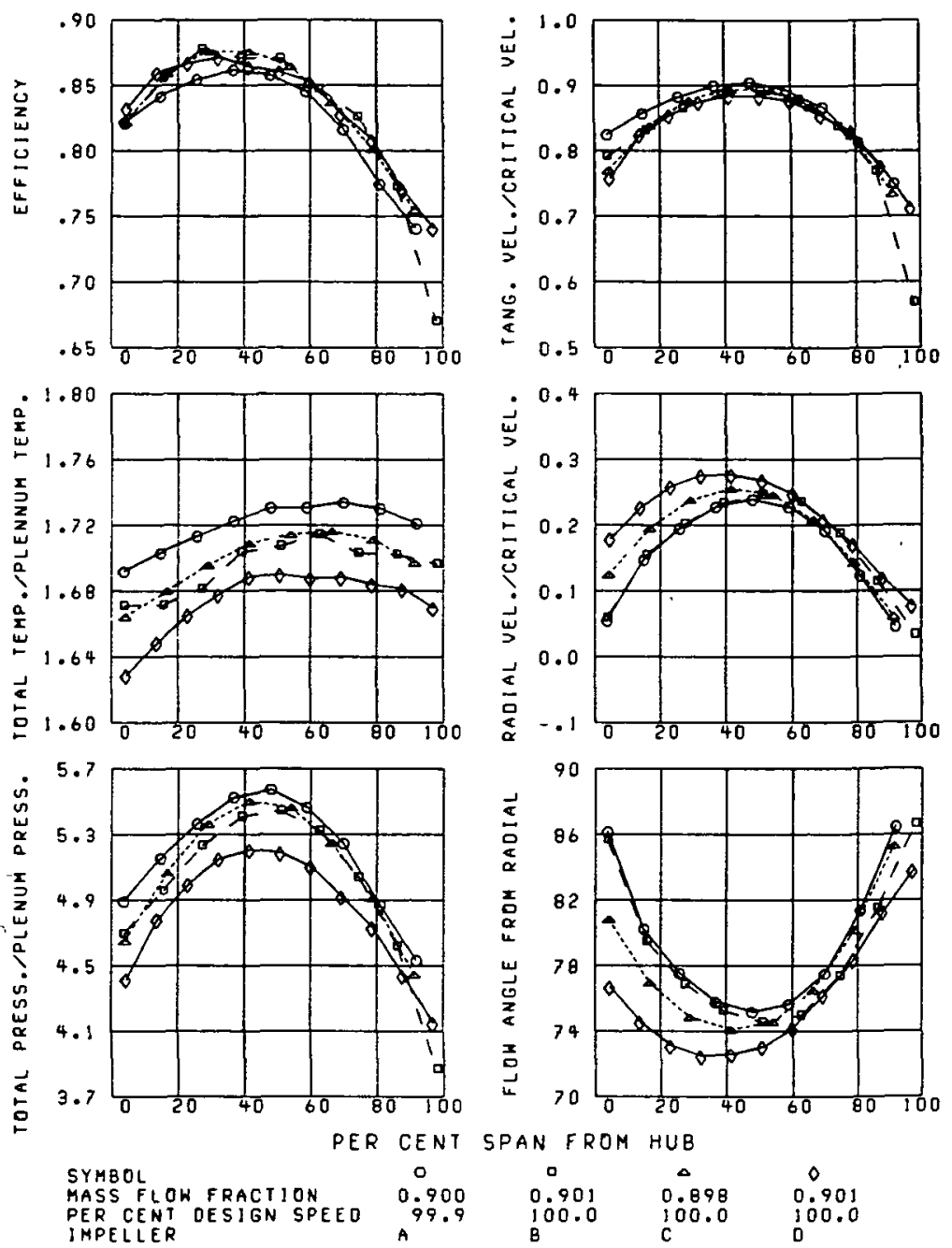

Figure 17. - Area ratio comparison - 100 percent speed small clearance. 


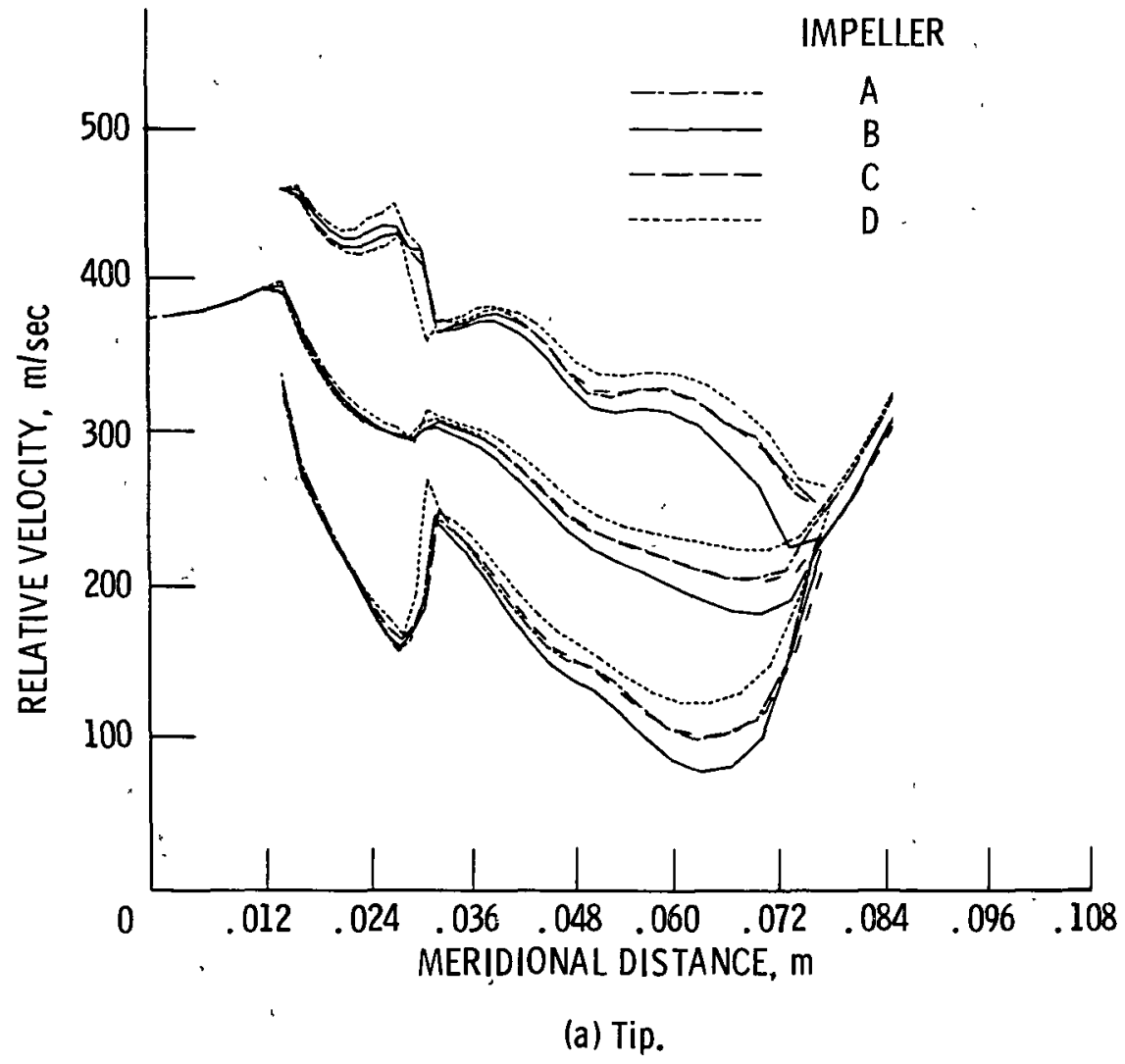

Figure 18. - Impeller loading diagrams for 100 percent design speed, $\dot{\mathrm{m}} / \dot{\mathrm{m}}_{\mathrm{DES}}=0.9, \mathrm{CL} \mathrm{b}_{2}=0.08$. 


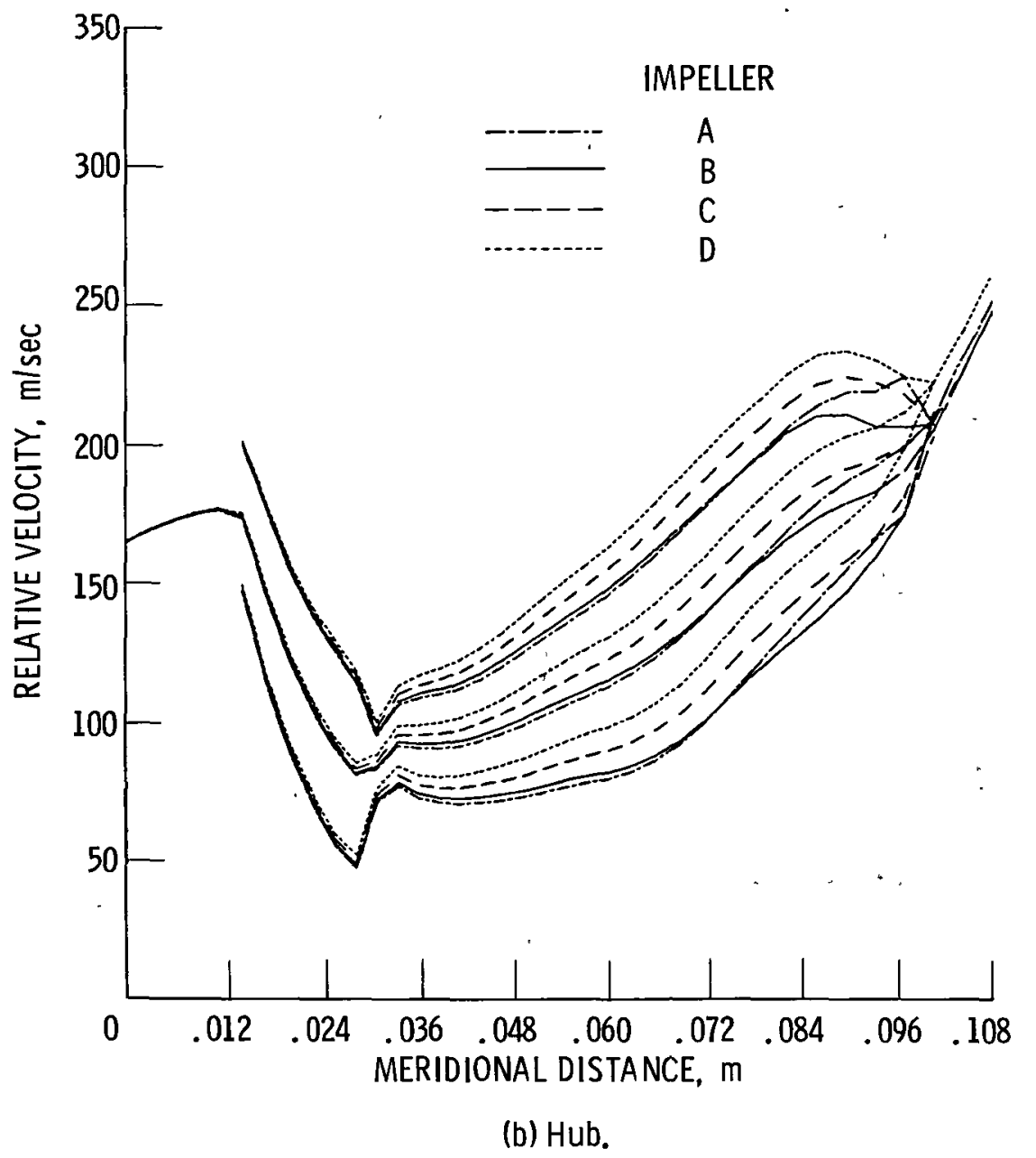

Figure 18. - Concluded. 


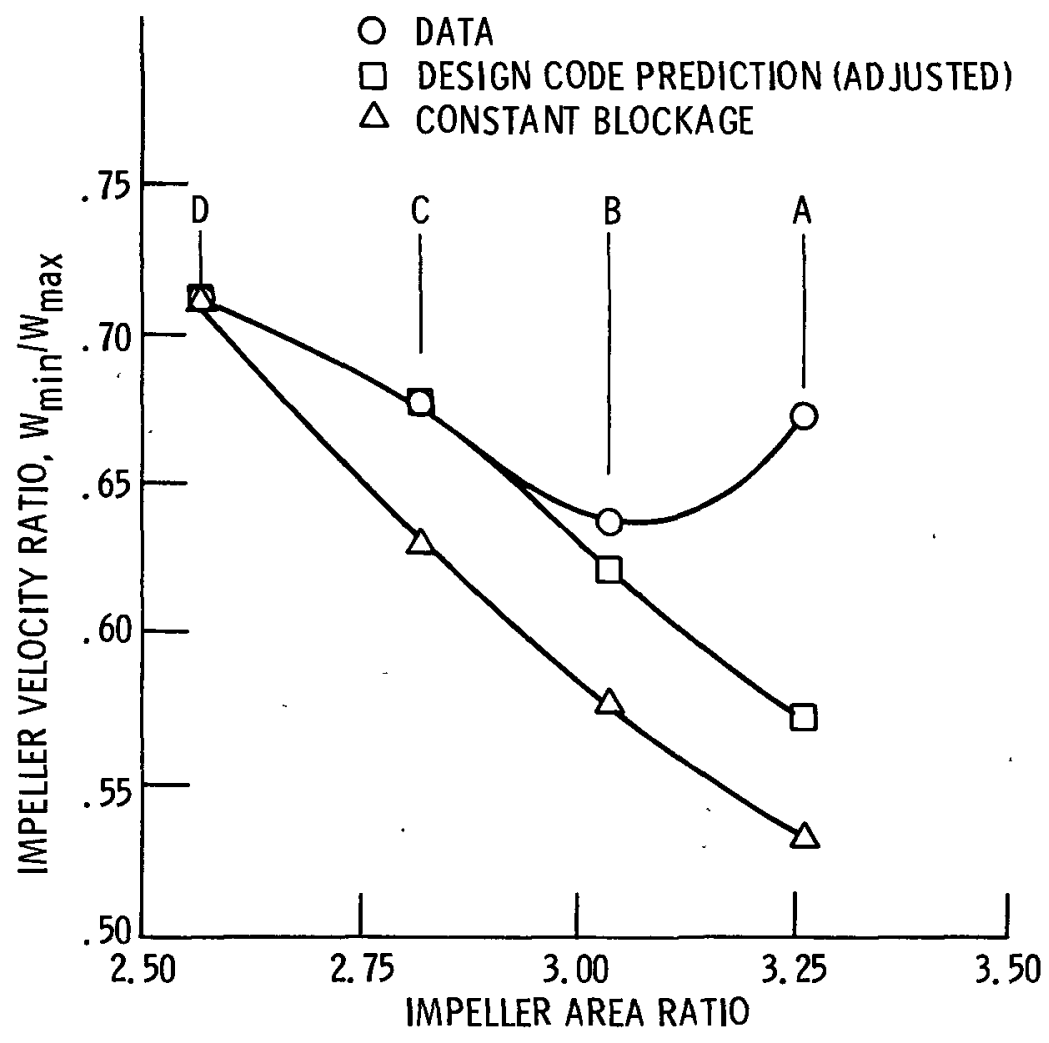

Figure 19. - Velocity ratio versus area ratio for design speed, $\dot{\mathrm{m}} / \dot{\mathrm{m}}_{\mathrm{DES}}=0.90, \mathrm{CL} / \mathrm{b}_{2}=0.08$. 


\begin{tabular}{|c|c|c|}
\hline $\begin{array}{l}1 \text { Report No. NASA TM-87237 } \\
\text { USAAVSCOM-TR-85-C-21 }\end{array}$ & & 3. Recipient's Catalog No. \\
\hline \multirow{4}{*}{\multicolumn{2}{|c|}{$\begin{array}{l}\text { 4. Title and Subtitie } \\
\text { Effect of Area Ratio on the Performance of a 5.5:1 } \\
\text { Pressure Ratio Centrifugal Impeller }\end{array}$}} & 5. Report Date \\
\hline & & \\
\hline & & 6 Performing Organization Code \\
\hline & & $505-62-22$ \\
\hline \multirow{3}{*}{\multicolumn{2}{|c|}{$\begin{array}{l}\text { 7. Author(s) } \\
\text { Lawrence F. Schumann, David A. Clark, and } \\
\text { Jerry R. Wood }\end{array}$}} & 8. Performıng Organization Report No. \\
\hline & & $E-2190$ \\
\hline & & 10. Work Unit No. \\
\hline \multirow{3}{*}{\multicolumn{2}{|c|}{$\begin{array}{l}\text { 9. Performing Organization Name and Address } \\
\text { NASA Lewis Research Center and Propulsion Directorate, } \\
\text { U.S. Army Aviation Research and Technology Activity - } \\
\text { AVSCOM, Cleveland, Ohio } 44135\end{array}$}} & \\
\hline & & 11. Contract or Grant No. \\
\hline & & 13. Type of Report and Period Covered \\
\hline \multicolumn{2}{|l|}{ 12. Sponsoring Agency Name and Address } & Technical Memorandum \\
\hline \multicolumn{2}{|c|}{$\begin{array}{l}\text { National Aeronautics and Space Administration } \\
\text { Washington, D.C. } 20546 \text { and U.S. Army Aviation } \\
\text { Systems Command, St. Louis, Mo. } 63120\end{array}$} & 14 Sponsoring Agency Code \\
\hline \multicolumn{3}{|l|}{ 15. Supplementary Notes } \\
\hline \multicolumn{3}{|c|}{$\begin{array}{l}\text { Prepared for the } 31 \text { st International Gas Turbine Conference and Exhibition, spon- } \\
\text { sored by the American Society of Mechanical Engineers, Dusseldorf, West Germany, } \\
\text { June } 8-12 \text {, } 1986 \text {. Lawrence F. Schumann and David A. Ciark, Propulsion Directorate, } \\
\text { U.S. Army Aviation Research and Technology Activity - AVSCOM; Jerry R. Wood, NASA } \\
\text { Lewis Research Center. }\end{array}$} \\
\hline \multicolumn{3}{|c|}{ 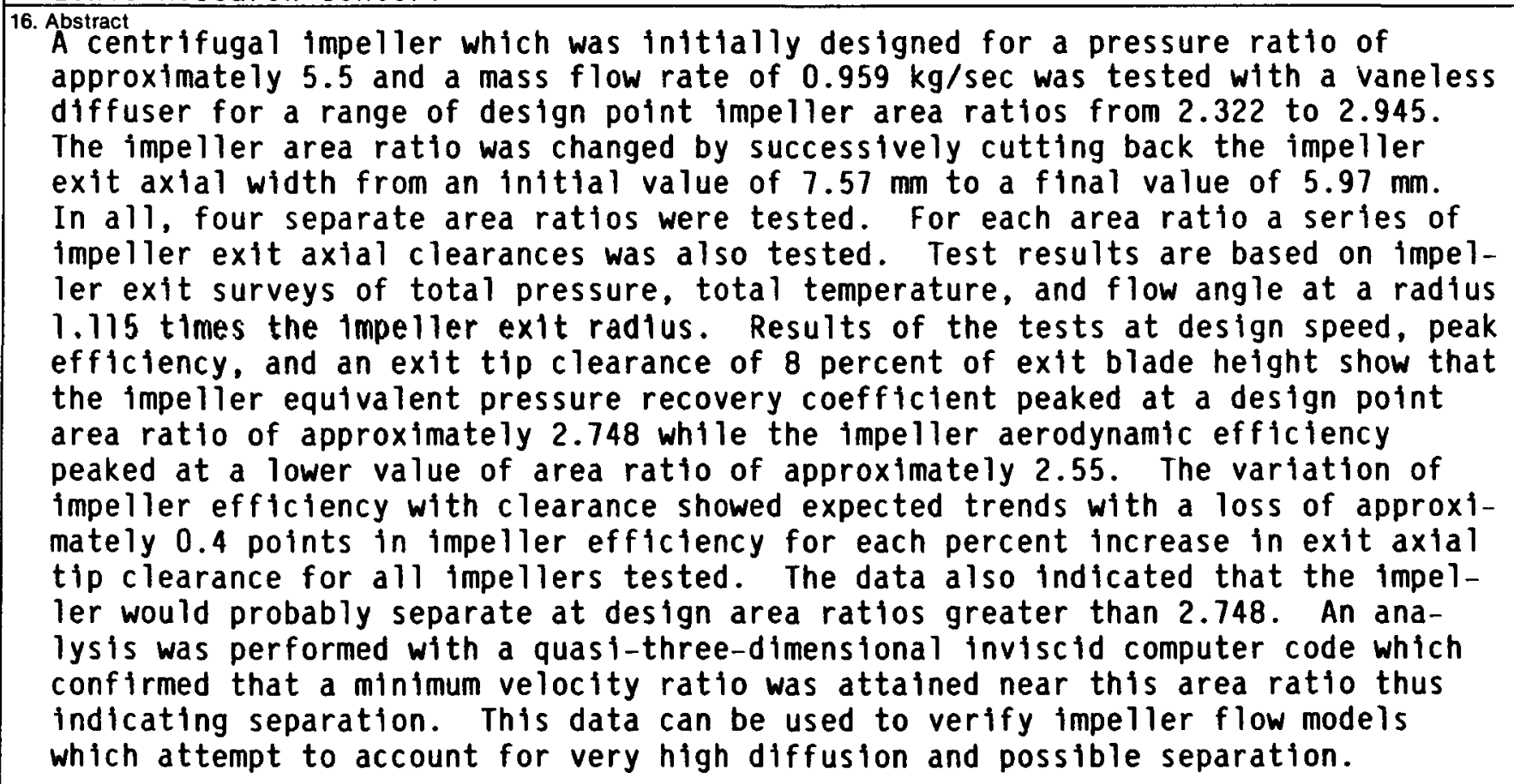 } \\
\hline \multicolumn{3}{|l|}{17 Key Words (Suggested by Author(s)) } \\
\hline \multicolumn{2}{|c|}{$\begin{array}{l}\text { Centrifugal compressor; Area ratio; } \\
\text { Clearance; Efficiency; Separation }\end{array}$} & $\begin{array}{l}\text { Unclassified - unlimited } \\
\text { STAR Category } 02\end{array}$ \\
\hline $\begin{array}{l}\text { 19. Security Classif (of this report) } \\
\text { Unc lass if ied }\end{array}$ & $\begin{array}{l}\text { Security Classif. (of this page) } \\
\text { Unc lass if fed }\end{array}$ & 21. No. of pages \\
\hline
\end{tabular}


National Aeronautics and Space Admınıstratıon

Lewis Research Center

Cleveland. Ohıo 44135

Orficial Business

Penalty for Pitvate Use $\$ \mathbf{3 0 0}$
SECOND CLASS MAIL

ADORESS CORRECTION REQUESTED

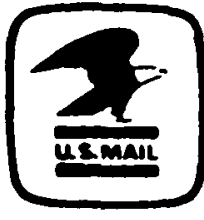

Postage and Fees Paid National Aeronautics and Space Administration NASA-451 